Portland State University

PDXScholar

5-19-1994

\title{
Changing Values: A Study of the Shift in Cultural Values and Perceptions of U.S. High School Students Following Orientation and Exposure to Russian Culture
}

Linda Sue Warnock

Portland State University

Follow this and additional works at: https://pdxscholar.library.pdx.edu/open_access_etds

Part of the Speech and Rhetorical Studies Commons

Let us know how access to this document benefits you.

\section{Recommended Citation}

Warnock, Linda Sue, "Changing Values: A Study of the Shift in Cultural Values and Perceptions of U.S. High School Students Following Orientation and Exposure to Russian Culture" (1994). Dissertations and Theses. Paper 4882.

https://doi.org/10.15760/etd.6758

This Thesis is brought to you for free and open access. It has been accepted for inclusion in Dissertations and Theses by an authorized administrator of PDXScholar. Please contact us if we can make this document more accessible: pdxscholar@pdx.edu. 


\section{THESIS APPROVAL}

The abstract and thesis of Linda Sue Warnock for the Master of Science degree in Speech Commumication were presented May 19, 1994 and accepted by the thesis committee and the department.

COMMITTEE APPROVALS:

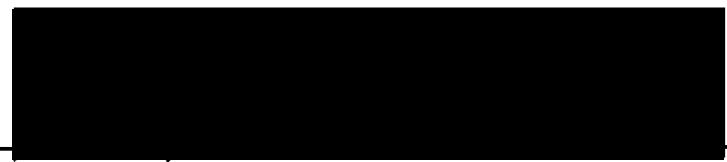

Larry A. Steward ,Chair

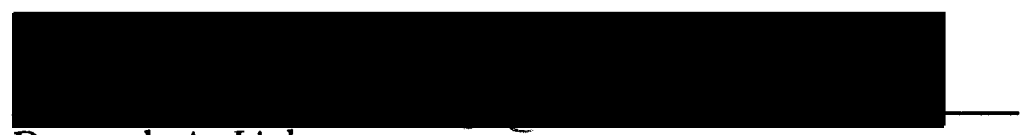

Devorah A. Lieberman

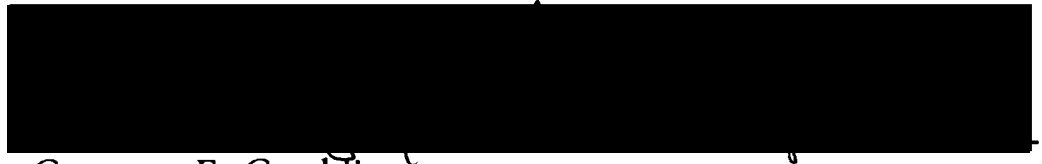

Gregory F. Goekjian

Representative of the Office of Graduate Studies

DEPARTMENT APPROVAL:

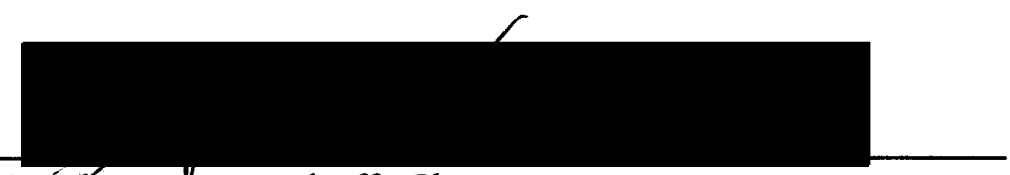

Stephen A. Kosokoff, Chair

Department of Speech Communication

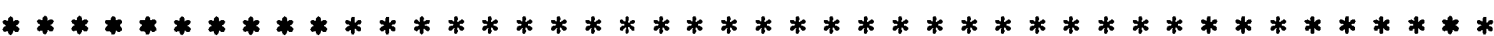

ACCEPTED FOR PORTLAND STATE UNNIVERSITY BY THE LIBRARY

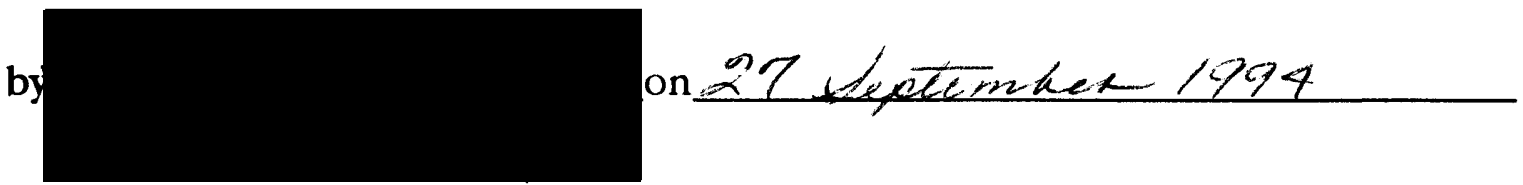




\section{ABSTRACT}

An abstract of the thesis of Linda Sue Warnock for the Master of Science in Speech Communication presented May 19, 1994.

Title: Changing Values: A Study of the Shift in Cultural Values and Perceptions of U.S. High School Students Following Orientation and Exposure to Russian Culture.

When cultural values differ, it is difficult for people not to judge one another's behavior on the basis of their own individual and/or cultural values. Given the profound differences in Russian and American culture, the question of what happens when these two cultures interact comes to mind.

The purpose of this study was to describe the relationship of culture specific orientation, coupled with a two week sojourn in Russia on the sojourners' perceptions of cultural values. The sojourners were high school athletes participating in the first part of a Russian - American Track and Field Exchange.

In order to ascertain the students' value orientations, each student completed six Value Orientation Worksheets. Before the pre-departure 
orientation the students' completed two worksheets composed of fifteen questions, one according to their own cultural values, and one for their perception of Russian cultural values. The students completed two additional worksheets after the pre-departure orientation sessions, and two worksheets ten months after the sojourn.

Analysis of the post-orientation worksheets suggests that the orientation sessions had a greater impact on the students' reported perceptions of their own cultural values than in changing their reported perceptions of Russian values. Unlike the post-orientation responses, an analysis of post-sojourn responses indicated that the sojourn experience appears to have had a comparable affect on the students' reported perceptions of their own cultural values and their reported perceptions of Russian cultural values. Post-sojourn worksheets revealed that agreement among the students after the shared orientation sessions was not a reliable predictor of agreement after the sojourn. In many cases, the individuality of the sojourn experience appears to have overcome the shared informational orientation training.

Continued research in this field is needed to determine whether or not the tendencies uncovered in this study can be generalized to include a wider population, specifically - American high school student/athletes traveling abroad for a short term sojourn. 

PERCEPTIONS OF U.S. HIGH SCHOOL STUDENTS FOLLOWING ORIENTATION AND EXPOSURE TO RUSSIAN CULTURE

by

LINDA SUE WARNOCK

A thesis submitted in partial fulfillment of the requirements for the degree of

\author{
MASTER OF SCIENCE \\ in \\ SPEECH COMMUNICATION
}

PORTLAND STATE UNIVERSITY

1994 


\section{ACKNOWLEDGEMENTS}

Heart felt thanks go to my family for their loving support through what has turned out to be a longer than expected journey through graduate school. To Kimberly who graduated from high school and went on to college, supporting and encouraging Mom from Texas; to Kristin for her hugs and understanding when I was discouraged; to Kelli whose journey through much of grade school and junior high paralleled Mom's trek through graduate school. Thank you my chickadees for your years of understanding and patience when Mom was in class or at the computer. And finally, to my life partner Ed without whose support this endeavor would not have been possible. For the technical support, for the 'permission' to close the office door and ignore the business, but most of all, for the underlying belief in me and my ability to "go the distance." 
TABLE OF CONTENTS

ACKNOWLEDGEMENTS $\ldots \ldots \ldots \ldots \ldots \ldots \ldots \ldots \ldots \ldots$ v LIST OF TABLES $\ldots \ldots \ldots \ldots \ldots \ldots \ldots \ldots \ldots \ldots \ldots \ldots \ldots$ vi LIST OF FIGURES $\ldots \ldots \ldots \ldots \ldots \ldots \ldots \ldots \ldots \ldots \ldots \ldots$ vii CHAPTER

I INTRODUCTION $\ldots \ldots \ldots \ldots \ldots \ldots \ldots \ldots \ldots \ldots$

II REVIEW OF THE LITERATURE $\ldots \ldots \ldots \ldots \ldots \ldots \ldots$

Key Concepts and Definitions $\ldots \ldots \ldots \ldots \ldots \ldots \ldots$

Perception Theory and Value Systems Theory in the

Context of the Intercultural Sojourn. $\ldots \ldots \ldots \ldots \ldots \ldots .12$

III U.S. AND RUSSIAN CULTURAL VALUES $\ldots \ldots \ldots \ldots \ldots \ldots 22$

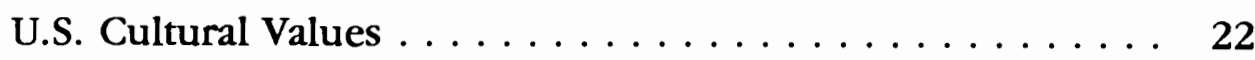

Russian Cultural Values $\ldots \ldots \ldots \ldots \ldots \ldots \ldots$

A Comparison of U.S. and Russian Cultural Values . . . . . . 44

Perception of the Self and the Individual $\ldots \ldots \ldots \ldots 45$

IV $\operatorname{RATIONALE} \ldots \ldots \ldots \ldots \ldots \ldots \ldots \ldots \ldots \ldots \ldots$

Research Questions ................. 50

Hypotheses $\ldots \ldots \ldots \ldots \ldots \ldots \ldots \ldots \ldots \ldots \ldots$

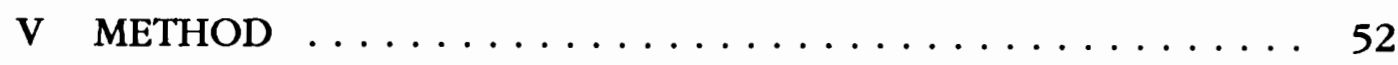

The Subjects $\ldots \ldots \ldots \ldots \ldots \ldots \ldots \ldots \ldots \ldots$ 
The Instrument $\ldots \ldots \ldots \ldots \ldots \ldots \ldots$

Data Collection ................... 56

Value Orientation Worksheet Analysis ........... 57

VI VALUE ORIENTATION WORKSHEET ANALYSIS . . . . . . . 60

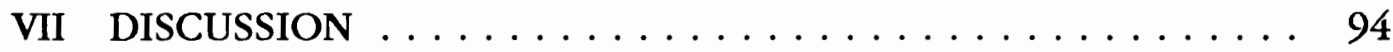

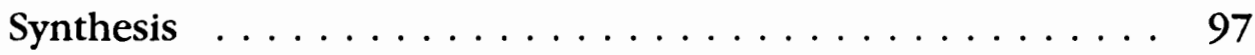

Epilogue . . . . . . . . . . . . . . . . . . . . 109

REFERENCES . . . . . . . . . . . . . . . . . . . 112

APPENDIX

Value Orientation Worksheet .............. 118 


\section{LIST OF TABLES}

TABLE

PAGE 


\section{LIST OF FIGURES}

FIGURE

PAGE

1. A comparison of the category shifts in the post-orientation

Russian and American Value Orientation Worksheets . . . . . . 64

2. A comparison of the category shifts in the post-sojourn

Russian and American Value Orientation Worksheets . . . . . . 64 


\section{CHAPTER I}

\section{INTRODUCTION}

Students have traveled abroad to study since the founding of the earliest universities. Following World War II, university-level travel and study abroad programs flourished, "so that by the mid-1960's, some two percent of the world's university students were studying abroad" (Eide, 1970). It was during this same time period that student exchange opportunities for secondary students became widely available. In 1983 , over eight thousand secondary students participated in the American Field Service International/Intercultural Exchange Programs. (AFS, 1983 Annual Report)

Each year brings new opportunities for students to participate in a cultural exchange, whether it be two months or 10 months under the AFS programs, a two week Spring Break trip with the school Spanish Club, or two weeks with a team of athletes traveling to China, Russia, or the Fiji Islands.

Regardless of the time span involved, a travel abroad experience is frequently viewed as an "excellent maturing and educational experience for young people" (Hansel, 1984, p. 1). Researchers over the past three decades have tested various hypotheses concerning the impact of a travel abroad program on the young people involved. The results are mixed. According to research done by Hansel (1984), most of the researchers were able to identify 
some changes which occurred as a result of the sojourn experience, but other factors were frequently involved (p. 2).

Significant factors which influence a student's experience include; the length of the sojourn, age, sex and nationality of the sojourner, frequency and contact with host nationals, activities of the sojourner while in the host country, attitudes and perceptions of the sojourner previous to the sojourn, and predeparture orientation.

This study will look at the relationship of culture specific orientation, coupled with a two week sojourn in Russia on the sojourner's perceptions of cultural values. The subjects are student athletes who will live with Russian host families while participating in mutual training and goodwill competition with their Russian counterparts. The focus of the study is the students' perception of both Russian cultural values, and their own personal values. The students will receive five, two hour orientation sessions prior to their departure, and one re-entry debriefing and sharing session upon their return.

Our perceptions of the world around us are heavily influenced by our cultural upbringing. What we assign importance to, even what we "see" is impacted by a combination of our experience and our value system in the context of our culture. For example, the passengers in an airplane flying over the same clearing among the trees, will "see" different things. Some will see a field for crops, others a long narrow meadow, a clearing for a new housing development or shopping center, or a ceremonial burial ground. The 
experienced bush pilot, on the other hand, will recognize the clearing as a landing strip, he/she has "seen" what the others have missed. The landing strip is obvious to him because of his experience, and his need to be able to find landing strips in isolated or mountainous terrain. For the bush pilot, knowing or recognizing potential landing strips is essential to his survival as a pilot. He will "see" what others do not. Our assumptions and perceptions of what we see and experience is grounded in our primary enculturation. We learn from the time we are infants what is acceptable and what is not, what is of value and what is not. All of our early training stands us in fairly good stead as long as we are interacting with people like ourselves. When we begin to interact interculturally whether at home or abroad, new sets of perceptions and values come into play.

As the world "shrinks" with faster modes of transportation and communication, coupled with an increase in the number of individuals traveling out of their home countries, the potential for misunderstandings and miscommunication increases. Bochner (1988) states that "when two people interact they do not merely respond to each other as individuals but as members of their respective groups. The actors behave according to the norms of the group they belong to, and they ascribe to the target person qualities that are supposed to be characteristic of that person's group" (p. 35).

All people have certain basic concerns. These are universal concerns relating to the way in which people view themselves, relate to each other, and 
their concept of their relation to the world in which they live. These concerns along with the need to secure food, clothing and shelter are "features of the human condition that are common to people everywhere" (AFS, 1981, p. 17). Grove (1989) calls this patterned, integrated whole - culture.

What distinguishes one culture from another is the manner in which it responds to these basic concerns. Individual cultures develop their own integrated pattern of responses which are reflected in the way in which people think and act. These responses are called value orientations. (AFS, 1981, p. 17) According to Grove (1989) the prevailing value orientations of a society have "an enormous influence on the daily lives of its individual members, for they are the shared 'rules' or 'recipes' that govern their habits of thought and patterns of behavior from moment to moment" (p.59).

One of the major sources of misunderstanding and conflict in intercultural interaction is our unconscious, deeply rooted and culturally conditioned perceptions of reality. "As long as our way of perceiving the world -- on which our communication styles and behavior patterns are based -is 'out of awareness', it is not accessible to being deliberately changed, understood, or influenced....This condition alters only as the individual becomes more aware and has more knowledge of the degree to which his perceptions and his behaviors are culturally conditioned -- that is, as he develops 'cultural self-awareness' (Hoopes, 1979, p. 16).

When cultural values differ, it is difficult for people not to judge another 
culture's behavior on the basis of their own individual and/or cultural values. (Borden, 1991). Sitaram and Haapanen (1979) in their work relating to the role of values in intercultural communication note: "the first rule of intercultural communication is that each participant should understand the other's values. That understanding should precede any attempts to communicate interculturally. Because communicative techniques are manifestations of one's own values, the participants communicate differently. The second is that each should adapt his/her communication to the other's values. Adaptation implies respect for the other value system" (p.159).

In the author's opinion, Sitaram and Haapanen's (1979) first rule of intercultural communication (understanding the other's values before attempting to communicate) is patently impossible. In the global world in which we live, if we wait to understand the values of all cultures who are different from our own, we will reduce our interactions to only those who we perceive to be like us. On the other hand, if we are aware of the fact that other value systems and world views exist, then we can begin to recognize that other solutions, different from our own, are possible and that the solutions adopted by our own culture are not the only reasonable ones.

Edward T. Hall (1966) speaks to this cultural awareness in stating that many of our cultural habits are hidden from ourselves, while being patently obvious to others. Communication is frequently thwarted because neither of the parties is aware of the fact that they inhabit different perceptual worlds. (p. 
5) Given the profound differences between Russian and American culture, the question of what happens when individuals from these cultures meet comes to mind.

\section{RESEARCH QUESTIONS}

The following questions are posed with respect to the preceding discussion.

1. Do U.S. sojourners report a change in personal value systems after a two week homestay in Russia?

2. Do U. S. sojourners report a change in perceptions of Russian Value systems after a two week sojourn in Russia?

3. To what extent are the Value Orientation Worksheets of the individual sojourners similar? (Do the student's answers indicate any sense of consensus, among themselves, concerning U.S. values?) 


\section{CHAPTER II}

\section{REVIEW OF THE LITERATURE}

This chapter begins with definitions of key concepts and terms as used in this research, followed by a discussion of areas which impact perception and value systems theory in the intercultural context. The chapter concludes with a comparison of American and Russian cultural values.

\section{KEY CONCEPTS AND DEFINITIONS}

The following terms will be used in the study:

Culture - "the sum total of ways of living; including values, beliefs, esthetic standards, linguistic expression, patterns of thinking, behavioral norms, and styles of communication which a particular group of people has developed to assure its survival in a particular physical and human environment..." (Hoopes and Pusch, 1979, p. 3).

Intercultural communication - "cultural variance in the perception of social objects and events" (Porter \& Samovar, 1988, p. 24). Intercultural communication takes place whenever "a message producer is a member of one culture and a message receiver is a member of another" (Porter \& Samovar, 1988, p. 15). 
Values - the evaluative aspect of our belief/value/attitude-systems. The way in which we assign a sense of "good" or "bad" to concepts in our culture. Cultural values - "a set of organized rules for making choices and reducing conflicts within a given society" (Porter and Samovar, 1988, Kluckhohn and Strodtbeck, 1961).

Perception - " the internal process by which we select, evaluate, and organize stimuli from the external environment" (Porter \& Samovar, 1982, p.36).

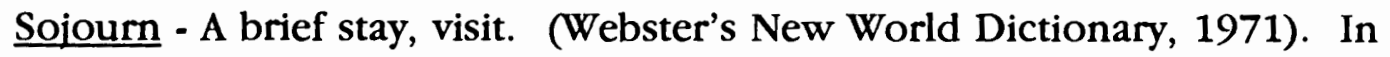
the context of this study, a two week visit to Russia in which case the sojourners reside in Russian homes.

American - A citizen of the United States. (Webster's New World Dictionary, 1971).

Areas which impact perception and value systems theory in the intercultural context include: an intercultural sojourn, culture, cultural value systems, perceptual frames of reference, belief/value/attitude-system, world view, social and cultural self-awareness, and social perception.

\section{THE SOJOURN}

Many of the studies concerned with the impact of travel abroad distinguished between the tourist who had very little contact with host nationals and those who became more deeply involved with the society in 
which they were visiting. Duncan (1978) and Cohen (1972) make distinctions between the 'mere tourist' and those with real cross-cultural experience. Cohen (1972) distinguishes between the institutionalized tourist who maintains a familiar environment while seeing new sights, and the non-institutionalized tourist who attempts to associate with the culture and the host nationals. Cohen (1972) indicates that while the institutionalized tourist gains only a superficial knowledge of the host country, possibly reinforcing stereotypes, the non-institutionalized tourist presumably gains a deeper understanding of the host country and its people. Boorstin (1961) makes a similar distinction between the traveler, who is working at gaining a deeper understanding of the culture, and that of the tourist who often gains a misleading and superficial understanding of the host culture.

The sojourners in this study are similar to Boorstin's traveler and Duncan (1978) and Cohen's (1972) non-institutionalized tourist. Although the U.S. students were part of an organized group, they studied Russian culture and shirthis values before their sojourn, and stayed in pairs with Russian families for the first week of their stay. During their second week they divided their time between host families and a Russian sports camp.

In studying short-term tourists, Pearce (1982) administered pre-test and post-test questionnaires to two groups of British tourists, one group traveling to Greece, and the other to Morocco. Pearce (1982) found that while differing somewhat from each other, both groups showed a number of changes. While 
both groups experienced a change in beliefs about the local people, Pearce (1982) found that the tourists' initial confidence in their beliefs influenced the changes which took place. He concluded that tourists on package tours tended to change their weakly held beliefs, but were generally consistent in maintaining the beliefs which they initially held with the most confidence. Pearce (1982) suggested however that the tourists' changes in beliefs could be linked to their "relaxation tourism motivation" (p. 213), since many of the changed beliefs could be linked to the specifics of the intercultural transactions in which the tourists participated (shopping, accommodations, food) (pp. 209212).

In continuing his discussion of the effects of intercultural contact on the tourist, Pearce (1982) documents two conflicting views of the effects of the travel experience on the 'tourists' themselves. On the one hand is the acquisition and promotion of tolerance and understanding of other cultures. Diametrically opposed is the view expressed by Huxley (1989) "we travel not that we may broaden and enrich our minds, but that we may pleasantly forget that they exist" (p. 18). The latter perspective concludes that the tourist experience is shallow and inconsequential, with little lasting effect on the traveller (Barthes, 1973; Turner and Ash, 1975).

Hansel (1984) refutes the tourist view as 'negative and inconsequential'. In her review of the literature concerning the impact of a travel-abroad experience, Hansel (1984) concludes that "those going abroad are likely to 
alter their views concerning the host country and return home with a different perspective of their own culture. This even occurs on a two-to three week package tour apparently" (p. 10).

Pearce (1988) concurs with Hansel, stating; "research indicates that tourists can modify their perceptions of their hosts, they can re-appraise selected aspects of their fellow countrymen, and they can emerge more confident in their beliefs about the host culture. In addition, the impact of the travel experience can alert tourists to the problems of inter-cultural interaction, through language and non-verbal communication difficulties" (p. 215).

Pearce (1988) concludes that while research concerning the impact of intercultural encounters on tourists is still "in its infancy", the current thinking is that even tourists who are not motivated by a desire to interact with the host culture, are influenced by the contact process (p. 217). In studies which researched the effects of the intercultural contact on the tourists themselves, attitudinal changes occurred as a result of the tourists' day-to day encounters with the host nationals. Central to these changes were the attitude and motivations for travel (Smith, 1955, 1957; Cook, 1962; Pearce, 1977).

Factors, which according to Hansel (1984), may make a "significant difference in the sojourn experience:

- length of the sojourn

- the frequency and quality of the contact with the host nationals

- the country and size of community in which the sojourn takes place 
- the age and sex of the sojourner

- the activities of the sojourner while in the host country

- the attitudes of the sojourner prior to the experience" (p. 10-11).

PERCEPTION THEORY AND VALUE SYSTEMS THEORY IN THE CONTEXT OF THE INTERCULTURAL SOJOURN.

Hoopes \& Pusch (1979) underline the importance of cultural awareness and values orientation when they state; "while perception is the core idea in intercultural communication, values are the bedrock of culture....The more we become conscious of the assumptions and values that govern our behavior, the better we are able to deal with the values we encounter in others" (p. 128). "As long as our way of perceiving the world--on which our communication styles and behavior patterns are based--is "out of awareness," it is not accessible to being deliberately changed, managed, understood, or influenced. It will continue to contribute to misunderstanding and conflict" (Hoopes (1979, p. 16). The review of the literature which follows will illustrate, in greater depth, the validity of Hoopes and Pusch's statements.

The bodies of literature most pertinent to this study are: Porter and Samovar (1988), Hofstede (1984), Schutz (1967), Hastorf (1973), Hoopes (1979), Grove (1989) Kluckhohn and Strodtbeck (1961) and Hall $(1966,1976)$. 


\section{Culture}

According to Grove (1989) when we take a broad look at human life, we might conclude that there are some basic human concerns which have faced humans since the beginning of time. These concerns involve "the way people view themselves as individuals, their relationships with others, and their relation to the natural and supernatural world in which they live" (p.59). Each society settles on one answer or another for each of the basic concerns. Grove (1989) goes on to state "there are complex reasons why the people living together at any given time and place settle on this or that for each of the basic concerns. We can be sure, however, that ... all of their answers taken together constitute a pattern or integrated whole, which is not only meaningful, but also workable for them" (p. 59). Grove (1989) calls this patterned, integrated whole - culture.

Porter and Samovar (1988) define culture as an "all-encompassing form or pattern for living" (p. 24). Hofstede (1984) states that "culture could be defined as the interactive aggregate of common characteristics that influence a human group's response to its environment" (p. 21). In referring to the importance of culture, Hall (1976) states that "one of the functions of culture is to provide a highly selective screen between man [sic] and the outside world. In its many forms, culture therefore designates what we pay attention to and what we ignore" (p. 85). Porter and Samovar (1988) concur with Hall, stating, "It is generally believed that people behave as they do because of the ways in 
which they perceive the world, and that these behaviors are learned as part of their cultural experience" (p. 24). These culturally determined designations then become part of our cultural value system.

\section{Cultural Values}

What are values, and how do they relate to culture? Rokeach (1973) defines values as specific types of belief that are central to the system, and act as life guides. According to Albert (1968) "a value system represents what is expected or hoped for, required or forbidden. It is not a report of actual conduct but is the system of criteria by which the conduct is judged and sanctions applied" (p.288). Porter and Samovar (1988) also speak of the prescriptive nature of values stating that they are the "rules for making choices and reducing conflicts within a given society" ( p.25).

Cultural values are those which tend to permeate a culture. "Cultural values usually are derived from the larger philosophical issues that are a part of a culture's milieu" (Porter and Samovar, 1988, p. 25). They are the defining parameters for what is good and bad, right and wrong, true and false, and so on. Cultural values as derivatives of the larger philosophical milieu are in turn derivatives of individual values which are themselves influenced by the larger, often unconscious permeation of the cultural norms within which we live. Lee (1966) uses the term "Self Reference Criterion" to refer to an unconscious reference to one's own cultural values. According to Lee (1966) this 
unconscious reference is "held by people of all cultures" (p. 11).

Lustig (1988) states: "cultures can exist only because their members follow predictable behavior patterns....These predictable behavior patterns, which are stable over time and which lead to roughly similar behaviors across similar situations, are based upon a form of mental programming called values" (p. 56).

As youngsters we experience cultural values through normative rules, or codes of conduct. Cultural values also modulate behavior, specifying which kinds of behaviors are important and which should be avoided. Porter and Samovar (1988) define cultural values as "a set of organized rules for making choices and reducing conflicts within a given society" (p. 25).

Within these organized sets of rules, which give order and structure to a culture, are our own internal images of how the world works (Hofstede, 1988; Borden, 1991; and Senge 1990). Hofstede (1988) refers to these internal images as "mental programming" (p.18). Senge (1990) calls them mental models, stating: "mental models are powerful in affecting what we do because they affect what we see. Two people with different mental models can observe the same event and describe it differently, because they have looked at different details" (p. 175).

Brislin (1976) concurs with Senge (1990): he states "people perceive pretty much what they want to or expect to perceive, screening out many contradictory impressions" (p. 12). This perception is based on an individual's 
mental programming. "Since our behavior is predicated on the mental image we create, rather than from objective facts, we must become aware of where these images come from. It is our culture that influences us to create the mental images we use in our interactions with others" (Borden, 1991, p.46). As we interact with others, our standard of comparison is our own set of values. According to Brislin \& Pederson (1976), "We observe others from our own unique point of view, comparing them with ourselves as the standard of "normal" (p.11).

It is this tendency to base our understanding of others' behaviors and beliefs on our own cultural value systems which leads to the majority of intercultural misunderstanding and conflict. We must recognize that "people in various times and places experience the world differently" (Schutz, 1967, p. 138).

\section{Perceptual Frames of Reference}

Within our culture we construct frames of reference to give structure and meaning to that which we experience. One's cultural belief system, coupled with life experience, and one's role in society all contribute to what Brunner (1958) has called the individual's "expectancy set"; or the pre-conceived frame within which an individual perceives situations and other people. If we are to make sense of others' actions and beliefs we must try to understand their perceptual frames of reference. According to Porter and Samovar (1988) there are three major socio-cultural elements which directly influence our 
perceptions and the meanings we develop for them: our belief/value/attitudesystem, our world view, and our social organization.

Belief/Nalue/Attitude-System. Beliefs as defined by Porter and Samovar (1988) are "individually held subjective probabilities that some object or event possesses certain characteristics....Culture plays an important part in belief formation" (p. 25).

"Values are the evaluative aspect of our belief/value/attitude-systems" (Porter and Samovar, 1988, p. 25). Hofstede (1980) defines value as, "a broad tendency to prefer certain states of affairs over others" (p. 18).

Beliefs and values are instrumental in the development of attitudes. Attitudes may be defined as "a learned tendency to respond in a consistent manner with respect to a given object of orientation. Attitudes are learned within a cultural context" (Porter and Samovar, 1988. p. 26). Porter and Samovar (1988) further state that our attitudes, and ultimately our behavior is shaped by the cultural environment which surrounds us. (p. 26)

World View. "This cultural element, though abstract in concept and description, is one of the most important elements found in the perceptual aspects of intercultural communication. World view refers to a culture's orientation toward such things as God, humanity, the universe, and other philosophical issues that are concerned with the concept of being" (Porter and Samovar, 1988, p. 26). World view influences a culture at a deep and often quite subtle level. World view issues endure through time, representing the 
most fundamental basis of a culture. For example, the world view of Native Americans "places them at one with nature. They perceive a balanced relationship between man and the environment, a partnership of equality and respect" (Porter and Samovar, 1988, p. 26). The "average", middle class, EuroAmerican places man at the center of the universe. "Because of their profound belief that humans are supreme and are apart from nature, they treat the universe as theirs--a place to carry out their desires and wishes through the power of science and technology" (Porter and Samovar, 1988, p. 26). Porter and Samovar (1988) go on to state that "world view spreads itself over a culture and permeates every facet of it" (p. 26). It is often quite subtle, revealing itself in a culture's values, beliefs, and attitudes, rather than in an obvious superficial manner such as gestures, dress, or vocabulary. World view is a potent influence on culture precisely because of this subtlety.

World view has a powerful influence on intercultural communication because as a member of a culture, an individual's world view is so deeply embedded in the psyche that it is taken completely for granted, and the individual assumes that everyone else views the world as they do. The individual possesses little if any self-awareness. (Porter \& Samovar, 1988, p. 26) Cultural Self-Awareness. An individual will begin to develop a "cultural self-awareness" as he/she becomes more aware and has more knowledge of the degree to which his/her perceptions and behaviors are culturally conditioned (Hoopes, 1979). Achieving cultural self-awareness or the ability to recognize 
one's own world view is not a simple process. Hoopes (1979) lists the following three reasons why we are inclined to resist achieving cultural selfawareness:

(1) Awareness is an emotional event derived from experience rather than an idea attained through an intellectual process. Yet we have generally been taught that the intellect is the principle avenue of learning. (2) We like to think of ourselves as autonomous and not subject, against our will to forces buried within us by our cultural heritage. (3) We are vulnerable. Anything that probes the nature of our identities is threatening. Even for those who pursue it, cultural awareness is elusive (p. 16).

Hoopes (1979) goes on to state that no matter how much experience we have, or how skillful we become in recognizing the cultural dimensions of human relations, we still frequently find ourselves "imprisoned in our own limited perceptions" (p. 17). Our resistance to self learning lies at an emotional, unconscious level and we are inclined to recognize the problem in others while denying it in ourselves. If we are to break through our cognitive defenses, we must recognize that "cross-cultural misunderstanding relates to us here and now rather than to 'them' out there" (Hoopes, 1979, p. 17). We must become aware of our own patterns of communication, our own behaviors, and our own cultural values and perceptions which so strongly influence and guide our behavior.

Social Perception. Within our perceptual frames of reference is what Simmons and McCall (1979) call social perception. Our perceptions of people will influence not only what we think about them, but also our interaction with them. Hastorf (1970) in speaking of the complexity of interpersonal [or 
intercultural interaction] states: "How you categorize and perceive me will influence how you behave toward me, and your behavior in turn, will influence how I behave" (p.13).

In their discussion of social perception, Simmons and McCall (1979) state that "...we can be said to interact, not with individuals, but with our images of them. We do not, after all have to deal with them directly as physical "things" but as objects that we have clothed with identities and meanings" (p.59). Harris and Moran (1986) concur with Simmons and McCall (1979) in recognizing that individuals form their own perceptions of people based on their personal cultural background, and life experience. Harris and Moran (1986) note that a person "should realize that his or her knowledge and perceptions are valid only for self and not for the rest of the world" (p. 53). Schutz (1967) concurs with Harris and Moran (1986). He focuses on the individual meanings which different people bring to a communication encounter. One of Schutz's assumptions is that individuals both perceive that their experience of the world is valid, and that their perception of events is accurate.

Simmons and McCall (1979) correlate the accuracy of perception with "social distance", stating that "we tend to perceive only the gross outlines of people and events that lie any distance from our own positions in the social structure" (p. 61). Our appraisals of those who are different from ourselves tends to be very superficial. "Just as buildings block our view of the next street 
so the relative insulation of strata and subcultures from one another partly obstructs the visibility of even those social positions that are fairly close to us" (Simmons \& McCall, 1979, p. 61). Schutz's (1967) approach assumes that "People, in various times and places, experience the world differently" (p. 138) or as Gorman (1977) states, "the world when filtered through my biographical situation, becomes my world" (p. 38).

If we accept the premises of Schutz and Gorman, then in the context of this study, it behooves us to look closely at the value systems of both Russia and The United States. How do Russian citizens and U.S. citizens filter the world? What underlying differences and similarities influence perceptions and behaviors? As we take a closer, in-depth look at Russian and U.S. cultural values it would serve us well to contemplate the words of French historian Frances Guizot (1955):

When nations have existed for a long and glorious time, they cannot break with their past, whatever they do; they are influenced by it at the very moment when they work to destroy it; in the midst of the most glaring transformation they remain fundamentally in character and destiny such as their history has formed them. Even the most daring and powerful revolutions cannot abolish national traditions of long duration. Therefore, it is most important, not only for the sake of intellectual curiosity but also for the good management of international relations, to know and to understand these traditions.

The next chapter contains an in-depth look at U.S. and Russian cultural values, ending with a brief comparison of these values. 
CHAPTER III

\section{U.S. AND RUSSIAN CULTURAL VALUES}

\section{U.S. CULTURAL VALUES}

How are U.S. cultural values defined in the light of the extraordinary ethnic diversity reflected in the population of the United States? According to Althen (1988) more than twenty percent of the population of Los Angeles and New York, were born in another country. In a number of our major cities "more than one out of every ten residents is foreign-born" (Althen, 1988, p. xii). The U.S. is not only diverse ethnically, but politically, socially, by religious preference, occupation, education, and ability, to name but a few.

Considering the diversity of the U.S., is it possible to speak of U.S. or "American" values? The answer is a qualified "yes." Kohls (1984) states, "when we talk of American...values, we mean those which predominate within that group; those which are held by enough of the members to make the value an evident and prominent part of the culture as a whole" (p. 22). Althen writes "Americans might all seem different from each other until you compare them as a group to the Japanese (for example). Then it becomes clear that certain values are much more characteristic of the Americans while others are far more 
typical of the white, middle class" (p. xiii). Althen continues by noting that the values which are typically thought of as "American" values are those of the white, middle class. Historically, people in this class have held the majority of the nation's most influential positions. It is becoming increasingly apparent that not all Americans are white, or middle class, but the ideals and values of American society have been forged by that group. (Althen, 1988, p. xiii)

In the context of the above statements, Kohls (1984, pp. 29-30) lists the following twenty basic American values:

\begin{tabular}{|c|c|}
\hline THRIFTINESS & WARINESS \\
\hline AGGRESSIVENESS & INITIATIVE \\
\hline PREPARATION FOR THE FUTURE & GOOD SPORTSMANSHIP \\
\hline CLEANLINESS & PRIVACY \\
\hline TIME THRIFTINESS & WORK ETHIC \\
\hline PRACTICALITY & PHYSICAL APPEARANCE \\
\hline FRUGALITY & PLEASANT APPEARANCE \\
\hline DILIGENCE & PHYSICAL POWER \\
\hline RESPONSIBILITY & ORIGINALITY \\
\hline PERSISTENCE & TIMELINESS OF ACTION \\
\hline
\end{tabular}

In order to probe more deeply into U.S. and Russian cultural values, the author has chosen to use a model developed by Kluckhohn and Strodtbeck (1961). This model looks at five basic questions dealing with a culture's value system.

1. Human nature orientation - What is the character of innate human nature? 2. "Man"-Nature orientation - What is "Man's" relation to Nature? 
3. Time orientation - What is the temporal focus of human life?

4. Activity orientation - What is the mode of human activity? (Kluckhohn and Strodtbeck, 1961, Kohls, 1984).

5. Social orientation - What is the mode of human relationships?

TABLE I

THE KLUCKHOHN MODEL

\begin{tabular}{|c|c|c|c|c|c|c|}
\hline ORIENTATION & \multicolumn{6}{|c|}{ RANGE } \\
\hline \multirow{2}{*}{$\begin{array}{l}\text { HUMAN } \\
\text { NATURE }\end{array}$} & \multicolumn{2}{|c|}{ BASICALLY EVIL } & \multirow{2}{*}{$\begin{array}{l}\text { NEUTRAL } \\
\text { MUTABLE }\end{array}$} & \multirow{2}{*}{$\begin{array}{c}\begin{array}{c}\text { MIXTURE } \\
\text { OF GOOD } \\
\text { AND } \\
\text { EVIL }\end{array} \\
\text { IMMUTABLE }\end{array}$} & \multicolumn{2}{|c|}{ BASICALLY GOOD } \\
\hline & MUTABLE & IMMUTABLE & & & MUTABLE & IMMUTABLE \\
\hline $\begin{array}{l}\text { MAN-NATURE } \\
\text { RELATIONSHIP }\end{array}$ & \multicolumn{2}{|c|}{ SUBJUGATION TO NATURE } & \multicolumn{2}{|c|}{ HARMONY WITH NATURE } & \multicolumn{2}{|c|}{ MASTERY OVER NATURE } \\
\hline TIME SENSE & \multicolumn{2}{|c|}{$\begin{array}{l}\text { PAST-ORIENTED } \\
\text { (TRADITION BOUND) }\end{array}$} & \multicolumn{2}{|c|}{$\begin{array}{l}\text { PRESENT-ORIENTED } \\
\text { (SITUATIONAL) }\end{array}$} & \multicolumn{2}{|c|}{$\begin{array}{l}\text { FUTURE-ORIENTED } \\
\text { (GOAL-ORIENTED) }\end{array}$} \\
\hline ACTIVITY & \multicolumn{2}{|c|}{$\begin{array}{c}\text { BEING } \\
\text { (EXPRESSIVE/EMOTIONAL) }\end{array}$} & \multicolumn{2}{|c|}{$\begin{array}{l}\text { BEING-IN-BECOMING* } \\
\text { (INNER DEVELOPMENT) }\end{array}$} & \multicolumn{2}{|c|}{$\begin{array}{c}\text { DOING } \\
\text { (ACTION-ORIENTED) }\end{array}$} \\
\hline $\begin{array}{c}\text { SOCIAL } \\
\text { RELATIONS }\end{array}$ & \multicolumn{2}{|c|}{$\begin{array}{l}\text { LINEALITY** } \\
\text { (AUTHORITARIAN) }\end{array}$} & \multicolumn{2}{|c|}{$\begin{array}{c}\text { COLLATERALITY*** } \\
\text { (COLLECTIVE DECISIONS) }\end{array}$} & \multicolumn{2}{|c|}{$\begin{array}{l}\text { INDIVIDUALISM***** } \\
\text { (EQUAL RIGHTS) }\end{array}$} \\
\hline
\end{tabular}

Explanations of terms used above:

* Being-in becoming-The personality is given to containment and control by means of such activities as mediation and detachment, for the purpose of the development of the self as a unified whole.

**Lineality-Lines of authority clearly established and dominant -subordinate relationships clearly defined and respected; Rights according to rank.

***Collaterality-man is an individual and also a member of many groups and sub-groups' He is independent and dependent at the same time.

****Individualism-Autonomy of the individual.

(Kohls, 1984, p. 84)

Kluckhohn and Strodbeck's model uses the word "man" throughout. The author in using this model as a framework for comparing Russian and American value orientations has adopted the same language. The term man in this context refers to the human race and is not intended to be either exclusive or sexist. 
Using the above model, Kohls (1984) has determined that "a typical middle-class/mainstream American" (p. 22) would generally be found to fall in the following categories:

\section{$\underline{\text { Human Nature }}$}

"Americans are generally optimistic, choosing to believe the best about a person until that person proves otherwise" (p.22). Americans would fall in the far right hand column, under "Basically Good." It should be noted that "the Kluckhohn's, however, placed Americans in the left hand column (basically evil), citing the Christian belief in original sin" (Kohls, 1984, p. 23). Stewart (1971) also describes North Americans as "evil but predictable;...man can change and improve self and it is his responsibility to do so" (p. ). Kohls goes on to state that although this may have been accurate for the 1950's, it seems "thoroughly antiquated" (p. 23) for today. Kohls (1984) further states that even if Americans see human nature as evil, there is a deep belief that human nature is changeable and that "humans and human society are ultimately perfectible-if only enough effort is made in that direction" (p. 23).

\section{"Man"- Nature}

Americans see a clear separation between man and nature. Man is considered to be the master of his own destiny. Kohls (1984) states that Americans "have an insatiable drive to subdue, dominate, and control their natural environment" (p. 23). 


\section{Time Orientation}

Americans consider time a resource that can be used well or squandered. Americans talk of saving, wasting, and spending time. Punctuality is a virtue, and youngsters are taught from early childhood that polite behavior includes being considerate of other people's time.

Americans are future-oriented. American thought and planning is dominated by a belief in progress. Americans are task and goal oriented, conscious that as the proverb states, "time is money." "Americans have an optimistic faith in the future and what the future can bring. We tend to equate 'change' with 'improvement' and consider a rapid rate of change as normal" (Kohls, 1984, p. 23). Americans admire the "well organized - efficient" individual. Althen (1988) writes, "the premium Americans place on efficiency is closely related to their concepts of the future, change and time. To do something efficiently is to do it in the way that is quickest and requires the smallest expenditure of resources" (p. 15).

\section{Activity Orientation}

Americans are action oriented, stressing 'doing' over 'being'. Kohls (1984) states that "Americans are so action oriented that they cannot even conceive what it would be like to be 'being' oriented...As a result of this action orientation, Americans have become very proficient at problem solving and decision making" (p. 23). 
$\underline{\text { Social Orientation }}$

Americans are individually oriented, stressing the importance of the individual and the equality of all people. Americans scorn rank and authority, preferring to be frank, informal, friendly, and outgoing. Kohls (1984) notes that "American bosses are the only supervisors in the world who would insist on being called by their first names by their subordinates" (p. 24).

In comparison to the rest of the world, American family ties are relatively weak. The American family is generally considered to be the smallest possible unit - the nuclear family. (Kohls, 1984, p. 24).

\section{RUSSIAN CULTURAL VALUES}

In 1939, Winston Churchill described Russia as a riddle, wrapped in a mystery, inside an enigma. (In Richmond, 1992, p. xxiii) We know a little more about Russia today with the advent of glasnost but much about the Russian people, their culture and values, remain a mystery. There are countless books, tapes, and articles available for the individual interested in learning about American culture and values. Information, in English, regarding contemporary Russian culture and values is not so readily available.

There are, at the present time, two great nations in the world which seem to tend towards the same end although they started from different points: I allude to the Russians and the Americans....The American struggles against the natural obstacles which oppose him; the adversaries of the Russian are men; the former combats the wilderness and savage life...The Anglo-American relies upon personal interests to accomplish his ends, and gives free scope to the unguided exertions and common sense 
of the citizens; the Russian centers on the authority of society in a single arm: the principal instrument of the former is freedom; of the later is servitude. Their starting points are different, and their courses are not the same; yet each of them seems to be marked out by the will of Heaven to sway the destinies of the globe" (Alexis de Tocqueville, 1835).

As far back as 1835 , Frenchman Alexis de Tocqueville was struck by the differences and the similarities between the Russians and the Americans. Many of the similarities are obvious. Both nations are great powers with a multiethnic citizenry. Both nations have an expansionist history. The Americans moved west from the Atlantic coast across the Great Plains and the Rockies to the Pacific. Russia expanded in all directions with the greatest expansion east beyond the Ural mountains, across the vast expanses of Siberia to the Pacific, and beyond to Alaska in 1741 (Richmond, 1992). "Sheer territorial size has been a dominant factor conditioning the Russian mentality for many centuries....Space, expansiveness--these, surely provide a vital key to the Russian character, since they have played such a great part in the country's evolution" (Hingley, 1979, p.29). Hingley (1979) goes on to note that, "in the century and a half between 1550 and 1700 Moscow was annually adding to her territory an area equal to that of modern Holland" (p.30).

Both nations tamed a wilderness. Despite the difficulties of travel, and the immense distances involved, "the availability of apparently infinite expanses of unused spaces in the south east and east has contributed to a nomad psychology in the Russian peasant" (Hingley, 1979, p.29). Hingley (1979) goes on to note that this sense of infinite space and the ability to roam throughout 
Russia's "wild east" influenced the Russian "obsession with untrammeled spaciousness which has often been cited as a feature of the Russians" (p.29). Hingley (1979) cites the reaction of Father Vasily, a native of Russia's central plains, to the spectacular Caucasus mountains. Father Vasily complained that there is 'no scenery' in these parts. When asked to explain his seemingly indefensible statement, Father Vasily is said to have replied that the wretched mountains got in the way. (Hingley, 1979, p. 30).

Richmond (1992) notes that "there is a frontier spirit shared by Siberia and the American West" (p. xxi). "Americans and Russians also think big. Both are energetic and inventive. Russians appreciate the casual, direct, and often blunt American way of speaking which they liken to their own--without pretense and much different from the West European manner which they find formal, indirect, and less sincere" (Richmond, 1992, p. xxi).

Some of the differences between Russians and Americans are as apparent as are the similarities. In comparing the development of Russia and the West, Hingley (1979) states, "Above all, Russia's development has diverged from that of the West in the evolution of state authority. As authoritarian rule has, however unevenly and sporadically, steadily declined in the West over the centuries, a marked contrary trend is to be observed in Russia from the fifteenth century onward..." (p.33). Authority in America flows upward - from the people to a representative government. In Russia, authority is centralized and flows downward. Change in Russia is imposed from above. In America, 
change tends to come from below, with elected officials either responding or being replaced.

In the United States the individual and individual rights are both protected and celebrated. In Russia, the American tolerance for pluralism and diverse views appears chaotic. The Russians "value consensus and a single prevailing truth" (Richmond, 1992, xxi). Hingley (1977) in writing about the Russian concept of truth states that according to Gorer $(1949$, p. 185) "the gradual discovery and application of the Truth (pravda) is the most significant activity of mankind." Hingley goes on to state that the Russian concept of truth is all the more relevant given the continual exposure to a dogmatic ideology which assumes that "in any given situation, however complex, there can be only one Truth" (Hingley, 1979, p.107).

Historical experience and geography have influenced both Russian and American culture. "The great rivers of Russia flow north and south, and along these rivers came Russia's early contacts with the outside world" (Richmond, 1992, p. 6). In the ninth century the Viking raiders and traders from the north became the rulers of Rus, "the city-principality of Kiev and forerunner of the Russian state" (Richmond, 1992, p. 6). From Russia's southern rivers came contact with Byzantium, the Eastern half of the Christian Roman Empire and the magnificent capitol of Constantinople.

With this contact came Russia's written language, religion, law, and art, all of which would play a vital role in the formation of Russian cultural values. 
Leonid Borodin in talking with David Shipler (1983) stated, "It is not possible to talk about Russian culture, about the remembrance of Russian culture, about painting, architecture, history, literature, that did not come from Russian Orthodoxy and all of its culture" (p. 330).

In writing about the influence of history on present day culture, Richmond (1992) traces Russia's historic distrust of the West back to the Tatar (Mongol) invasion in 1234 and 1240. "While the Tatar conquest did not make Asians of the Russians, it did prevent them from becoming Europeans. It also produced today's Russians--a mixture of Slavic, Finnish, and Tatar blood" (Richmond, 1992, p. 6). With the liberation of Moscow in 1480, the modern Russian state was born. "Distant from Europe the new state was cut off from Constantinople which in 1453 had fallen to the Muslim Ottoman Turks" (Richmond, 1992, p. 7).

Separated from the West, Russia experienced none of the major developments which shaped modern Europe, neither Luther and the Reformation, with its pluralism of religious and secular thought, nor the Renaissance are paralleled in Russian history (Hingley, 1979; Willis, 1985). During the Renaissance, while Europe was seeing the growth of big cities, the emergence of Michelangelo, da Vinci and Erasmus, the development of modern agriculture and commerce, the scientific revolution, the growth of economic liberalism coupled with individual rights, the stirrings of political liberty, and the growth of a strong middle class, "Russia was still struggling with the Tatar 
menace" (Hingley, 1979, p.33).

In the West it was the middle class which was at the forefront of reform (Richmond, 1992; Hingley, 1979). "Russia's failure to develop a strong middle class delayed reform" (Richmond, 1992, p. 7).

Cut off from the West, Russia remained a vast, backward [from the western point of view], largely agricultural empire, regimented and ruled by an autocratic dynasty with a holy mission to defend its faith against the barbarians of the East and the heresies and pluralism of the West (Richmond, 1992, p. 7).

It is with this background of history, and geography that we will look at Russian cultural values. As George Vernadsky writes:

All civilizations are to some extent the product of geographical factors, but history provides no clearer example of the profound influence of geography upon a culture than in the historical development of the Russian people. (In Richmond, 1992, p. 5)

In attempting to extrapolate Russian cultural values from the small body of literature on contemporary Russian life and culture, the author has chosen to use the same categories as were used in the discussion of American cultural values.

\section{Human Nature}

When asked what Americans should know to better understand Russians, Davydov, a contemporary Russian poet answered, "In our cold winter each opening of the door is a repetition of dying. Russians do not fear death because every day is a struggle. It is a pity to die, and a pity not to die" (In Richmond, 1992, pp. 41-42). "Life has been difficult for Russians. Weather, 
wars, violence, cataclysmic changes, and oppressive rule have made them pessimists" (Richmond, 1992, p. 41).

Americans tend to be optimistic, expecting things to go well. Children are taught to "keep smiling" even through adversity. Russians expect life to be hard, and things to go poorly, and have learned to live with misfortune. They are suspicious of the "smiling" Americans and consider the American eternal optimism to be naive. When Richmond (1992) asked a Russian professor about the rationale behind his pessimism, the professor answered, "Our main concern, that which determines all our actions and feelings is strabk (fear). The world is dangerous, and we must be careful" (p. 41).

Shipler (1983) relates Russian cultural values to Russia's largest children's store, Detsky Mir ("Children's World"). It is here he writes that "the earliest values take place in plastic and tin...." From the shelves stacked with centrally planned playthings, the newest members of the society are introduced to the physical world, guided in their games, taught the rules" (p. 51). Shipler goes on to write that the toys at Detsky Mir as well as other children's stores around the country are heavy on military themes and educational functions, and their displays "define unambiguously the roles for boys and girls" (1984, p. 52). Toys for boys are predominately military equipment, guns, and sports equipment. Toys for girls include tea sets, cradles, little washboards, toy vacuum cleaners, etc. "The common denominator of all the toys is that they break easily...these first possessions rarely last long, and as they crack and bend 
and splinter, they teach something about the child's powerlessness over his world, fostering a sense of material things as expendable and unworthy of strong attachment" (Shipler, 1983, p. 53). Shipler (1983) goes on to state that these flimsy toys incur terrible disappointment and anger. The larger consequence though is "their usefulness in promoting ultimately a numbness and fatalism conducive to later contentment within an adult system that is also physically deprived and unresponsive to individual desires" (Shipler, 1983, p. 53).

"Man" - Nature

Where Americans see a clear separation between "man" and nature, with man clearly in charge, Russians are much more likely to believe that man is driven and controlled by Fate and can do very little, if anything to influence it.

Custine (1839) wrote:

The aim of civilization in the North is serious. There, society is the fruit, not of human pleasures, not of interests and passions easily satisfied, but of a will ever persisting and ever thwarted which urges its peoples to incomprehensible efforts. There, if individuals unite together, it is to struggle with a rebellious nature, which unwillingly responds to the demands made upon her.

Russia is a northern country. Its southern port of Odessa is further north than Minneapolis. According to Richmond (1992) Russia's harsh climate "explains the Russians' strength, their ability to endure extreme hardship, and their bleak outlook on life as well as their patience and submission" (p. 9). The harsh climate has also made them cautious. Russias' weather is unpredictable, and in a land largely dependent on agriculture, risk taking is viewed as 
imprudent.

Richmond (1992) goes on to ask the question, "Does climate still make a difference in the final years of the twentieth century" (p. 9)? Over time, people in all parts of the world have adapted to their environment, some even "taming" it. Americans with their plethora of air conditioning, central heating, and tightly insulated homes have insulated themselves from the extremes of weather. Americans living in the arid southwest live much as their American cousins in the cold northeast. Most Russians, however, have lived until recently much as their agrarian ancestors did - in small isolated villages, their freedom of movement restricted both by the weather and the restrictions of the mir, without the creature comforts and labor-saving tools provided by modern society. (Peabody, 1985; Richmond, 1992)

\section{Time Orientation}

As noted in the discussion of American values, for Americans, time is money, and punctuality a virtue. For the Russian population, with their agricultural heritage, "time is like the seasons--a time for sowing and a time for reaping, and a time for doing little in between" (Richmond, 1992, p. 112).

Mead (1951) writes, "Punctuality has been exceedingly difficult to instill into a population unused to regular hours..." (p. 95). The Russian disregard for time has also been influenced by the years under Communist rule. Under Communism "workers cannot be fired and there is no incentive to do things on time" (Richmond, 1992, p. 122). Though Russian watcher Klaus Mehnert states 
that the Russian concept of time is changing, with young Russians becoming more "sensitized to the chronological dimension"..., to the excessively timegeared Westerner, Russia still seems to operate in an atmosphere relatively emancipated from the clock, resembling Spain rather than Germany, Britain, or America in this respect" (Hingley, 1979, p.43).

The Russian approach to interpersonal communication also influences the concept of time. In a business meeting, there are a number of rituals which must be followed before the business part of the meeting can start: all personal encounters begin with the small talk, followed by the customary tea or other beverage, followed by more small talk about the family and personal matters; and finally the business of the day.

Unlike the direct approach favored by Americans, Russians follow a more roundabout approach. Even after agreement has been reached, nothing may happen for weeks or even months. "For Russians, time is not measured in minutes or hours but more likely in days, weeks, and months. The venerated virtue [value] in Russia is not punctuality but patience" (Richmond, 1992, p. 123).

\section{Activity Orientation}

As noted in the previous discussion of American cultural values, Americans are oriented toward doing. Russians on the other hand are oriented toward thinking. When faced with an issue that needs resolution, a Russian will most likely think through the historical, philosophical, and ideological 
considerations along with the consequences before taking any action.

Americans will be most interested in the "practical points, the obstacles to overcome, the details, and how to get from here to there" (Richmond, 1992, p. 123). It should be noted that though Richmond refers to Russians as thinkers rather than doers, this thinking is along very rigid and narrow lines. Robert Kelley, a history professor at University of California, found significant blind spots among faculty and students he encountered during a semester of teaching at Moscow State University. "They tend to approach subjects formally, structurally--when studying William Jennings Bryan, they study the structure of the party. Teaching them is like trying to explain physical illness to a society that has never had it. They have never come down with democracy" (Shipler, 1984, p.369). In attempting to explain American individualism to his Soviet colleagues, one Soviet professor responded, "That's very undisciplined. That's bad for your army. You don't have an idea. Russians have an idea. Russians need an idea to believe in" (Shipler, 1984, p. 369). What these Russian professors were missing, according to Shipler (1984) was "that the essence of the American idea is in the din of ideas" (p. 369).

\section{Social Orientation}

Americans value success, we raise our children to work hard, get ahead, strive to be successful in whatever they do. The success ethic according to Richmond (1992) is an alien concept to the Russians who believe that it may be "morally wrong to get ahead, particularly at the expense of others" (p. 33). 
Egalitarianism in Russia advocates both the equal distribution of benefits and the removal of inequities between people. Russian egalitarianism has its roots in the culture of the mir; "an agricultural village commune... based on territory and mutual interests. Members lived in small hamlets, in huts side by side. The surrounding land was held in common by the mir, and was unfenced" (Richmond, 1992, p. 14). "Before the introduction of currency, mir members were economically equal and equality for members was considered more important than freedom" (Richmond, 1992, p. 34). Richmond goes on to state that for much of Russian history, approximately ninety percent of the Russian population were peasants, tied to the land. These agricultural communes "with their egalitarian lifestyle and distribution of material benefits, were seen by many Russian intellectuals as necessary to protect the simple peasants from the harsh competition of Western individualism" (Richmond, 1992, p.34). It was feared that the promotion of individual rights would enable the strong to prosper, while the weak suffered. (Richmond (1992) notes that Russian egalitarianism should not be confused with the American concept of equal opportunity, and equality of all people before the law.)

Along with egalitarianism, many other aspects of Russian cultural values can be traced back to the mir. Unlike the American "one man one vote", decisions in the mir were made by an assembly of village households. All members could speak, with eventual consensus, the lack of opposition being the ultimate objective. No votes were taken and the resulting decision was 
binding on all households.

"The mir endured in various forms until 1930 when it was replaced... by the Soviet collective farm: (Richmond, 1992, p. 17). Russian peasants have been tied to the land for hundreds of years. Tikhomirov wrote in 1888 "The Great Russian cannot imagine a life outside his society, outside the mir...The Great Russian says: 'The mir is a fine fellow, I will not desert the mir. Even death is beautiful in common" (Miller, 1981).

Shipler (1984) in writing about the collective and the individual states that the submersion of a sense of individuality and personality, whether it be in the factory, a scientific institution, rows of schoolchildren, or the entire nation is "much more than a fragment of Marx and Engels polished by Lenin and stuck like an irritating splinter into Russian flesh. It has been absorbed into the structure of values and mores so that its violation stimulates genuine revulsion in many people" (pp. 71-72). Scientists who push against the flow and seek financing of unorthodox projects are labeled egotists, not achievers. If a child were to set up a lemonade or kool-aid stand as many enterprising American youngsters do, he/she would be immediately shut down and scolded severely for "engaging in an activity seen as simultaneously demeaning and self centered" (Shipler, 1984. p. 73).

In Russia the commune is a normal part of life, in America the commune is considered unusual and alien. Individualism is held in high regard in America: we teach our children that they should strive to be the very best - to 
stand out from the crowd. In Russia, individualism has a pejorative meaning. The Russian collectivist spirit is eloquently expressed in an old Russian proverb: "In a field of wheat, only the stalk whose head is empty of grain stands above the rest" (Shipler, 1984, p. 73). According to the Russian who shared this proverb with Mr. Shipler, it was a "beautiful statement, one that touched the essence of human affairs and reflected the transcendence of traditional communal impulses over modern communist doctrine, thereby rooting the ideology firmly in Russian soil" (Shipler, 1984, p. 73).

According to Shipler, (1984) everywhere one goes in Russia, the individual is expected to blend in without any rough edges. Indeed, the statement, "he is not a good collectivist" becomes a stain which is almost impossible to remove. Shipler (1984) goes on to state that in the Soviet system of ethics, the collective is thought to bring forth the finest qualities in people. Even in stage or film portrayals of the collective's destructive power, the idea of collectivism is never attacked, rather there is a sense that something noble has been perverted. The Western values of individualism never gains ascendancy. No matter what the outcome of the story--happy or sad, the moral remains the same: "The collective is a potent force that can bring great good if used correctly" (Shipler, 1984, p. 85). Shipler (1984) gives many more examples of this collective spirit, from parents and teachers sharing equal responsibility for a child's performance in school, music teachers who are held responsible for the proficiency of their students, to medical students who are rarely flunked out 
because their professors' prestige would suffer. Factory managers as well as heads of research facilities are held responsible for the political behavior of their subordinates. (pp. 85-87).

Immersed in the traditions of the mir, Russians think of themselves as members of a community rather than as individuals. Peabody (1985) states that while authority provides the framework for moral rules, initiation, direction, and organization in relation to performance, individuals within the group provide emotional support. "There is a profound acceptance of group membership and relatedness, unthreatened by mutual dependence" (Peabody, 1985, p.151). According to Richmond (1992) this sense of a communal spirit helps to explain other Russian characteristics: Russians stand much closer than Americans when talking and are not upset with physical contact in crowds, an anathema to most Americans. Russians are not shy about intruding in the private affairs of others. Older Russians will admonish young men and women who are complete strangers, for perceived wrong doings. If a Russian is alone in a restaurant, he/she will not hesitate to join a complete stranger rather than dine alone at an empty table as most Americans would prefer. Where Americans value individual space, and seclusion, in Russia it is impossible to find the Russian equivalent for the English word "privacy" as the concept simply does not exist in the Russian language (Hingley, 1979; Shlapentokh, 1989). Hingley (1979) cautions the outsider however to not build too many inferences on the lack of an equivalent Russian word for the English word private. 
Hingley (1979) states "there can be no doubt whatever that most of them [Russian citizens] vastly prefer, constantly seek, and sometimes achieve a place of their own....The average Russian does not put up with queuing for use of the gas ring out of a talent for spiritual oneness with humanity. He does so because he has no choice" (p. 126).

Expanding on the apparent contradiction of the lack of a equivalent Russian word for the concept of privacy, Hingley (1979) asserts that living as they do in a society which encourages citizens to make their neighbor's business their own, Russians develop special skills in cultivating seclusion. "A private Russian may, perforce, be comparatively rare: but he tends to be a very private person indeed" (Hingley, 1979, p. 127). Shlapentokh (1989) notes that the process of privatization combined with the mass movement of Russians out of communal apartments into individual apartments has led to "the emergence and spread of the concept of privacy in Soviet life. It has begun to become one of the major personal values of the Soviet people" (p. 181-182).

As one observes the similarities and differences between Russians and Americans one must keep in mind the risks one takes in attempting to define national characteristics. There are always exceptions to the rule. As Richmond (1992) and Althen (1988) indicate in their work, the characteristics and values which they have isolated will not apply to either all Americans or all Russians. I would make the same claim. The following chart is an extrapolation, by the author, of Russian and American values and characteristics gathered through a 
review of the literature. It should also be noted that Russia is a vast, ethnically diverse nation, in the midst of rapid, and in some cases profound, change. The perceptions of Russian values as detailed in this study, are just that, perceptions and observations, made in large part by non-Russians. 
A COMPARISON OF U.S. AND RUSSIAN CULTURAL VALUES

\begin{tabular}{|c|c|}
\hline WOI & VIEW \\
\hline U.S. & RUSSIAN \\
\hline $\begin{array}{l}\text { Individualism } \\
\text { - Democratic - authority flows } \\
\text { upward to a representative } \\
\text { government } \\
\text { - Pluralism } \\
\text { - Optimism } \\
\text { - Comparative judgement } \\
\text { - Man can modify nature for his } \\
\text { own ends } \\
\text { - Time is linear } \\
\text { - Future orientation } \\
\text { - The new is welcome } \\
\text { - Truth is relative } \\
\text { - Risk takers }\end{array}$ & $\begin{array}{l}\text { - Time is circular } \\
\text { - Tradition/past orientation } \\
\text { - The old is revered } \\
\text { - Truth is absolute } \\
\text { - Cautious, conservative - } \\
\text { defenders of the status quo } \\
\text { - Agrarian based society }\end{array}$ \\
\hline
\end{tabular}




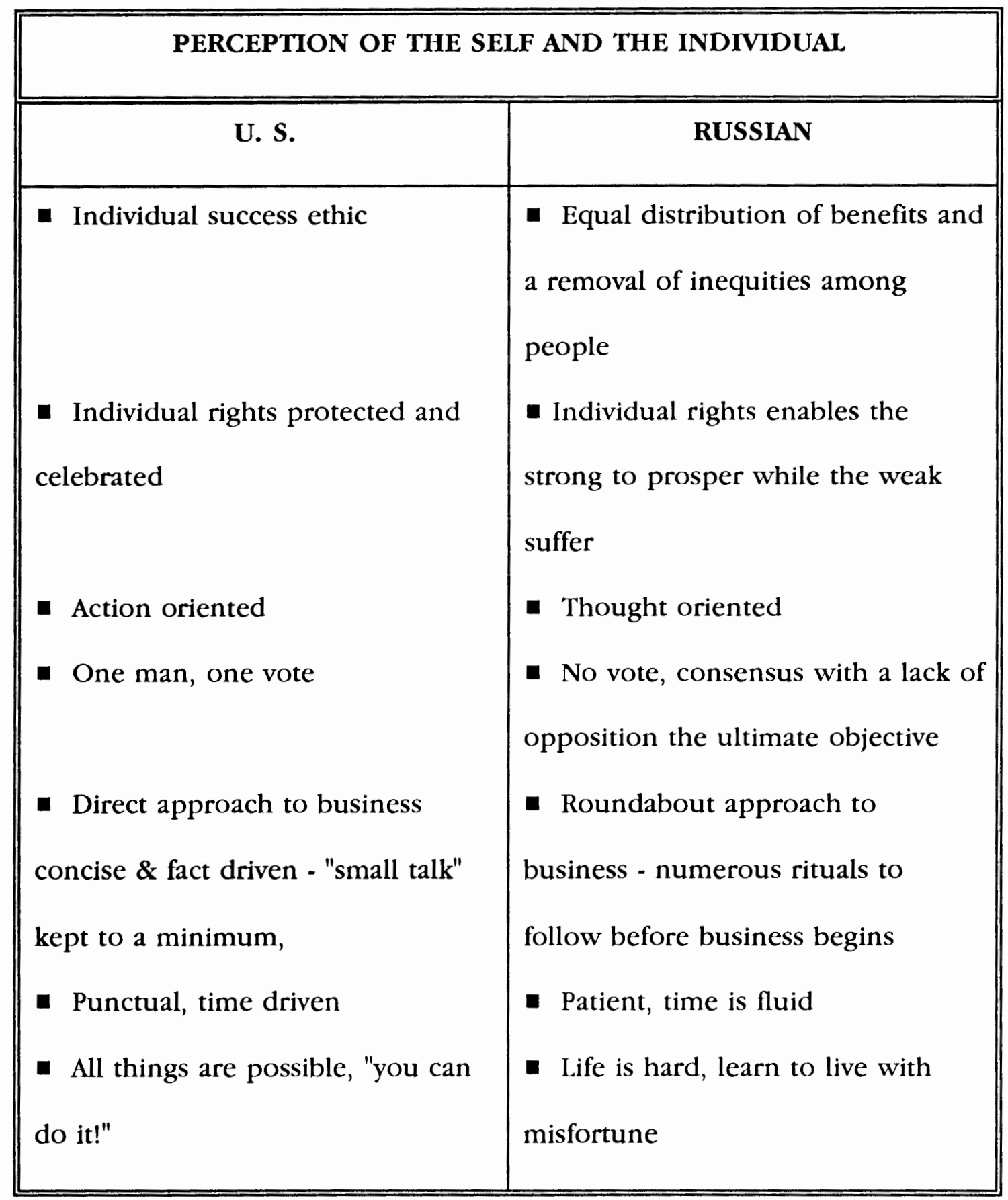


In comparing the differences in U.S. and Russian cultural values, and

perceptions we would do well to contemplate the words of French historian

Frances Guizot (1955):

When nations have existed for a long and glorious time, they cannot break with their past, whatever they do; they are influenced by it at the very moment when they work to destroy it; in the midst of the most glaring transformation they remain fundamentally in character and destiny such as their history has formed them. Even the most daring and powerful revolutions cannot abolish national traditions of long duration. Therefore, it is most important, not only for the sake of intellectual curiosity but also for the good management of international relations, to know and to understand these traditions. 


\section{CHAPTER IV}

\section{RATIONALE}

Much research has been done on the effects of long-term cultural exchange programs, (AFS, 1983, 1986; Hoffman \& Zak, 1969; Kagitcibasi, 1978; Leonard, 1964); Nash, 1976; Smith, 1951; Vornberg \& Grant, 1976) but there is very little research on the impact of short-term cultural exchange programs. Previous studies focussed on (1) the benefits to adolescents of an intercultural homestay based on anecdotal evidence or (2) studies which identified several personal characteristics or "outcomes" in which students were compared with a control group which expressed an interest in an intercultural homestay, but were not able to participate (AFS, 1986).

Central to this study is the work of Pearce (1988), Kluckhohn and Strodtbeck (1961), Hofstede (1984), Porter and Samovar (1988), and Grove (1976). Pearce (1988) states that future research effort in the field should be "directed towards a controlled assessment of short - and long term contact effects, with particular attention to the motivation and precise features of the contact situations...For the present, the field is characterized by adequate postboc descriptions of observed social and psychological effects, but has little to offer from the view of a priori assessment and prediction" (pp. 217-19). Pearce (1988) also suggests that more study needs to be conducted in order to test 
theoretical principles of tourist-host contact.

In his study of the effects of a two to three-week package tour, Pearce (1988) found that even in such a short time, the travelers showed a number of changes in attitude and beliefs toward the host country. Pearce (1988) goes on to state that; "While research concerning the impact of inter-cultural encounters on tourists is still in its infancy, the current position is that tourists, even without the specific motivation of wanting to meet and interact with the locals, can be influenced by the contact process " (p. 216).

If this is the case, what then of the tourist or sojourner whose motivation is to both interact and compete with host country nationals? The researcher was confronted with an opportunity to respond to this question when a local organization contacted high school track and field athletes in the Portland, Oregon metropolitan area concerning a two week sojourn in Russia.

The athletes who responded to this invitation to be part of a RussianAmerican Track and Field Exchange came from four area high schools. The attributes which drew them together were an interest in traveling abroad, combined with the opportunity of getting a first hand glimpse of how Russian athletes train and compete. My connection with the exchange came through two people. The first, was the athlete who brought the invitation to participate in the exchange to my attention. The second individual was one of the administrators with Golden Troika, the organization which initiated the exchange. In contacting Golden Troika, I discovered that this individual was a 
colleague in the Intercultural Communication field. It was through our mutual interest in Intercultural Communication that I was able to join with Golden Troika in observing the affects of the pre-departure orientation and the sojourn on the value orientations of the participating students.

The focus of this study is the relationship of a short-term sojourn on the perceptions and values of the sojourner. Unlike the studies reviewed in Chapter II, this study will look at not only the sojourn experience on the cultural value orientations of the sojourner; it will also look at the influence of shared culture specific pre-departure orientation. According to Pearce (1988) research indicates that not only can tourists [sojourners] modify their perceptions of their hosts, begin to re-evaluate aspects of themselves and their fellow-countrymen, but also emerge more confident in their beliefs about the host culture (p. 215). In addition, Pearce notes that "the impact of the travel experience can alert tourists to the problems of intercultural interaction, through language and non-verbal communication difficulties" (p.216).

The students participating in the Russian - American Track and Field Exchange will not only have the opportunity to experience the problems of intercultural communication connected with language and non-verbal communication of which Pearce (1988) speaks, but will also be confronted by the whole gamut of cultural differences connected with an intercultural homestay. The purpose of this study is to add a small grain of knowledge to this emerging field. 


\section{RESEARCH QUESTIONS}

1. Is there a change in the student's reported perceptions of Russian cultural values after the pre-departure orientation?

2. Is there a change in the student's reported perceptions of their own cultural values after the pre-departure orientation?

3. Is there a change in the student's reported perceptions of Russian cultural values after the sojourn in Russia.

4. Is there a change in the student's reported perceptions of their own cultural values after the sojourn in Russia?

5. Is there any agreement among the students? 1. Pre-orientation, 2. Post orientation, pre-departure, 3. post sojourn.

6. If there was agreement before the pre-departure orientation, did postorientation results indicate the same level of agreement?

7. If there was agreement among the students' responses before the sojourn, did post-sojourn results indicate the same level of agreement?

8. Was there more change in the students' reported perceptions of their own values, or of their reported perceptions of Russian cultural values?

\section{HYPOTHESES}

1. There will be observable shifts in the individual student's reported perceptions of Russian values after the five pre-departure orientation sessions. (Value Orientation Worksheet - Russian, pre-departure \#1, and Value 
Orientation Worksheet - Russian, pre-departure \#2).

2. There will be observable shifts in the student's reported perceptions of Russian Values following the sojourn in Russia, (Value Orientation Worksheet - Russian, pre-departure \#2, compared with Value Orientation Worksheet Russian, \#3 - re-entry.)

3. There will be observable changes in the personal values orientation worksheets of the students, (Value Orientation Worksheet - American values, pre-departure \#1 compared with pre-departure \#2, and pre-departure \#2 compared with \#3 re-entry.) 


\section{CHAPTER V}

\section{METHOD}

This is a descriptive study, the purpose of which is to describe reported perceptions relating to the cultural value systems of a group of American high school students traveling to Russia for a two week sojourn. The students completed a questionnaire composed of fifteen questions relating to cultural values. In conjunction with a description of the students' own cultural value systems, this study will compare and contrast the students' reported perceptions of how they believe their Russian counterparts would respond to the same set of questions relating to cultural values.

According to Tucker, Weaver and Fink (1981) "descriptive research paints a picture of the status quo or the current state of affairs. It depicts or characterizes current conditions" (p. 90). This study used what Rubin, Rubin and Piele (1986) term "purposive" sampling, a "known group of respondents that might be compared in the future" (p. 62). Purposive sampling is a nonprobability technique which, while not permitting generalizations, is useful for studying a particular group of people. Due to the small number of subjects, this study is classified as an exploratory study.

As noted previously, there is very little data concerning short-term sojourns. This study looks at the relationship of the pre-departure orientation, 
and the sojourn itself, on the students' perceptions of American and Russian cultural values. In order to provide a baseline from which to work the author chose The Value Orientation Worksheet as the test instrument.

\section{THE SUBJECTS}

The subjects for this study were seven U.S. high school student athletes between the ages of fifteen and seventeen who participated in a cultural exchange program with Russian track and field athletes in the Russian cities of Khabarovsk, and Birodibzhan. They stayed with Russian host families and competed in track and field goodwill games. Seven of the participants are females, one participant is male. All of the participants participated in this exchange by personal choice.

The exchange was facilitated by Golden Troika Enterprises, an Oregon based firm specializing in cultural and business exchange with the Russian Far East.

\section{THE INSTRUMENT}

In order to look at the dimensions (Time orientation, mankind's relation to nature, etc.) discussed in the Literature Review, the researcher chose the Value Orientation Worksheet. The conceptual origins of the Value Orientation Worksheet can be traced to F. Kluckhohn and F. L. Strodtbeck's (1961) Variations in Value Orientations, and E. C. Stewart's (1971) American Cultural 
Patterns: A Cross-Cultural Perspective. The Value Orientation Worksheet used in this study was developed by Cornelius Grove of the American Field Service (AFS) in 1982 for use with students preparing for an intercultural homestay. "It is a variation of the contrast-culture (or contrast-American) technique associated with Stewart and others..." (AFS, 1987, p. 58). According to C. Grove (personal communication, October 25,1993 ) variations of the Value Orientation Worksheet have been used extensively for several years, and it is well known as a useful instrument in the [intercultural communication] field. (The Value Orientation Worksheet used in this study was developed in 1982, a business version is also available.)

The objectives of the Value Orientation Worksheet as developed by Grove (1982) are threefold: "(1) To enable participants to become more fully aware of the nature of culture and of cultural differences. (2) To increase participants' understanding of the range of differences between and among cultures. (3) To improve the skill of the participants at correctly identifying the predominant values of their own culture (or some other culture)" (AFS, 1987, p. 56).

As used in this study, The Value Orientation Worksheet had a two-fold purpose: (1) to help the student discover what solutions have been adopted by his/her own culture with respect to the basic concerns of all people, and in so doing acquaint the student with alternative solutions adopted by other cultures. (2) Provide a means of describing any shifts which occur in the students' 
perceptions in relation to their own value systems as well as their perceptions of Russian values.

"Preparing young people for an intercultural homestay [sojourn] is difficult because the majority of them have never been immersed in an unfamiliar culture for an extended period of time" (AFS, 1987, p. 56). The American Field Service Orientation Handbook (1987) goes on to state that it is almost impossible to convey to people with no previous experience a satisfactory understanding of the nature of cultural differences" (p. 56).

The Value Orientation Worksheet was developed to assist the facilitator in overcoming this training challenge. The power of the Value Orientation Worksheet "lies in the impact upon its participants of seeing their own culture's choices treated equally with other alternatives for dealing with the same concern: some participants begin to grasp the arbitrariness of cultural choices" (AFS, 1987, p. 56).

According to C. Grove (personal communication, October 25, 1993) the Value Orientation Worksheet has not been used by AFS as a test instrument to measure change in value orientation. It was developed as an aid in predeparture orientation programs and was not subjected to any pilot testing. This author was not able to find any critical review of the Value Orientation Worksheet.

The Value Orientation Worksheet will be administered by an administrator with Golden Troika as part of the pre-departure orientation and 
re-entry debriefing sessions with the students. The facilitator is experienced in international sports exchanges and has extensive education and experience in Russian culture. She is a charter member and former president of the PortlandKhabarovsk Sister City Association. As a founding partner of Golden Troika, the facilitator both travels several times a year to Russia and facilitates Russian groups visiting the United States.

\section{DATA COLLECTION}

In order to begin unveiling the value orientations and cultural habits about which Hall (1966) writes, each student completed The Value Orientation Worksheet six times. The worksheet was administered for the first time during the first orientation meeting, before the students began their orientation sessions (pre-departure \#1). At this time each student filled out two Value Orientation Worksheets, one reflected their own cultural values, the second their perception of Russian cultural values. After the students completed their orientation sessions, and before they departed for Russia, they again completed two Value Orientation Worksheets, one for themselves, and one according to their perception of Russian cultural values (pre-departure \#2). Nine months after the students returned from Russia, they completed the final two Value Orientation Worksheets, once for themselves, and once according to their perceptions of Russian values (\#3 - Re-entry). (The researcher chose nine months as the time to administer the final Value Orientation Worksheet because 
it allowed for an assessment of the long-term affects of the orientation and sojourn before the students had any contact with the Russian athletes who traveled to the U.S. for the second half of the exchange.)

\begin{tabular}{|c|c|c|c|c|c||c||}
\hline \multicolumn{2}{|c|}{ Pre-departure Orientation Sessions } & $\begin{array}{c}\text { Sojourn in } \\
\text { Russia }\end{array}$ & $\begin{array}{c}\text { Re-entry } \\
\text { Orientation }\end{array}$ \\
\hline 1 & 2 & 3 & 4 & 5 & 6 \\
\hline $\begin{array}{c}\text { Value } \\
\text { Orientation } \\
\text { Worksheet - } \\
\text { pre- } \\
\text { departure \#1 }\end{array}$ & & $\begin{array}{c}\text { Value } \\
\text { Orientation } \\
\text { Worksheet } \\
\text { pre- } \\
\text { departure \#2 }\end{array}$ & $\begin{array}{c}\text { Value } \\
\text { Orientation } \\
\text { Worksheet \#3 } \\
\text { Re-entry }\end{array}$ \\
\hline
\end{tabular}

The Value Orientation Worksheet questionnaire is based on a Likert type scale of 1.0 - 3.0. Participants marked their answers anywhere along the continuum. Responses were scored on the continuum at intervals of .5 .
1.0
1.5
2.0
2.5

See appendix A.

\section{VALUE ORIENTATION WORKSHEET ANALYSIS}

The Value Orientation Worksheet Analysis is a reflection of the students' responses across six Value Orientation Worksheets, three relating to American values, and three relating to Russian values. The individual student's responses were entered into a computer database according to the number of the Value Orientation Worksheet (ie: Pre-departure \#1 - Russian Values, Pre-departure \#2 
- Russian Values, \#3 Re-entry - Russian Values), the student's identification number, and the number of the question. The resulting table was eighteen columns wide (three identifiers and fifteen questions) with forty-two rows.

The responses were then sorted into a table of the twenty-one responses for each question. The first column represents the individual's response for the pre-orientation worksheet (pre-departure \#1), the second column reflects the response for the post-orientation worksheet (pre-departure \#2) and the third column the individual's response on the post-sojourn worksheet (\#3 re-entry). The process was repeated for the three Value Orientation Worksheets dealing with the students' perceptions of American values.

The first phase in the analysis process was to determine whether or not there was observable movement between the pre-orientation worksheets (Value Orientation Worksheet - Pre-departure \#1 - Russian Values), and the postorientation worksheets (Value Orientation Worksheet - Pre-departure \#2 Russian Values). (This analysis process was followed for each of the fifteen questions.)

Phase two looked at the movement between the post-orientation worksheets (pre-departure \#2) and the post-sojourn worksheets (\#3 re-entry). If there was movement, the responses were analyzed to determine if the movement resulted in a change in categories - phase 3.

Any shift of .5 or above (for example, a 1.2 to a 1.7) or any shift which moves the response from one whole number to another whole number, (such 
as from 1.0 - past orientation to 2.0 - present orientation) is considered a change in category. For example, a pre-orientation mark of 1.1, on question II/3 (see Appendix A) regarding an individual's primary orientation with respect to time, would indicate that the respondent perceived of his/her Russian counterpart as being past oriented. A mark of 1.6 (a .5 shift) on the post orientation worksheet would be indicative of a category change. (A response of 1.6 falls midway between 1.0 and 2.0 indicating a perception that the past and present are of equal importance.) A shift from 1.1 on the pre-orientation worksheet, to 1.3 on the post-orientation worksheet, while observable, is not considered a change in categories. Hereafter, when speaking of a change of categories, the preceding discussion and definition of a category change will apply.

The responses were then tabulated to ascertain the total number of shifts (per question) phase 5, the total number of category changes - phase 6 , and the direction of the shifts - phase 7. The process was then repeated for the three Value Orientation Worksheets - American Values. 


\section{CHAPTER VI}

\section{VALUE ORIENTATION WORKSHEET ANALYSIS}

This chapter begins with a discussion of the hypotheses statements, followed by a detailed analysis of the fifteen questions from the Value Orientation Worksheet, concluding with a brief summary of the results.

\section{HYPOTHESES STATEMENTS}

1. There will be observable shifts in the individual student's reported perceptions of Russian values after the five pre-departure orientation sessions. (Value Orientation Worksheet - Russian, pre-departure \#1, and Value Orientation Worksheet - Russian, pre-departure \#2).

An analysis of all fifteen of the questions revealed observable shifts in the students' reported perceptions of Russian values after the orientation sessions. A minimum of five students showed movement in all of the questions, with all seven students showing movement in five of the questions.

There were ninety-two observable shifts out of a possible one hundred and five. (If all seven students had shifted their responses on all questions the total number of shifts possible would be one-hundred and five.) Out of the ninety-two shifts, thirty-two of the shifts moved the response into a category different from the response marked on the previous worksheet. 
Five of the seven students' post-orientation responses on the Value Orientation Worksheets - Russian Values, revealed a change in categories for questions $\mathrm{I} / 4$ What is the most generally approved procedure by which people arrive at conclusions and make decisions?; $1 / 5$ What is primarily valued and respected in individuals? and II/5 How do people usually relate to others of bigher or lower social status? Analysis of questions I/2 What do individuals tend to assume about the role of fate (chance) in their lives?; and $\mathrm{II} / 2$ How are personal disagreements and conflicts usually dealt with? reveal category changes for four students. A detailed analysis of these shifts follows in the next section.

2. There will be observable shifts in the student's reported perceptions of Russian Values following the sojourn in Russia, (Value Orientation Worksheet - Russian, pre-departure \#2, compared with Value Orientation Worksheet Russian, \#3 - re-entry.)

As in the pre-departure worksheets, post sojourn responses revealed shifts in all fifteen questions. In nine of the questions, six students responded differently than in the post-orientation worksheets, seven students shifted in four of the worksheets, and five students shifted in two of the questions. Of the ninety-two observable shifts, sixty-one of those shifts resulted in category changes.

Six of the students' worksheets revealed a category change for questions I/1 To what extent are people generally assumed capable of personal 
improvement?; 1/6 On what basis do people most often judge procedures and events?; and II/2 How are personal disagreements and conflicts usually dealt with? Five of the students' worksheets revealed a category change for questions $\mathrm{I} / 5$; What is primarily valued and respected in individuals?; and III/3 To what extent are material things and the fruits of buman progress assumed to be available to buman beings? The significance of these five questions will be discussed in the detailed analysis section.

3. There will be observable changes in the personal values orientation worksheets of the students, (Value Orientation Worksheet - American values, pre-departure \#1 compared with pre-departure \#2, and pre-departure \#2 compared with \#3 re-entry.)

Analysis of the questions relating to the students' reported perceptions of their own American cultural values, prior to their sojourn in Russia, revealed that like the Russian worksheets, there was observable movement in the responses in all of the questions. All seven students exhibited movement for three of the questions. Of those twenty-one observable shifts, sixteen of the shifts moved the student's response into a different category than previously chosen. Of the remaining sixty-one observable shifts, twenty-six of those responses moved the student's response into a different category than previously chosen. Six students shifted in five of the questions, five for four questions, four in two of the questions, and three students' shifted their responses in the remaining question. 
Questions which evoked, post-orientation, category changes for four of the students were; 1/1 To what extent are people generally assumed capable of personal improvement?; I/3 What effect does one's sex tend to bave on the responsibilities and roles in the family, among friends and co-workers, and in society?; $\mathrm{I} / 1$ What type of relationship with others tends to be suggested by the terms "friend" and "friendship"? and II/3 What is the primary orientation of people with respect to time? In question II/6, To what extent do people tend to feel bound or obligated by their membership in a particular family or clan?, six of the seven students moved into a different category from the one chosen in the pre-orientation worksheets.

Post-sojourn analysis of the Value Orientation Worksheets - American Values (pre-departure \#2 worksheets and \#3 re-entry) revealed sixty-five observable shifts with forty-three of those moving the student's post sojourn response into a different category than the previous pre-sojourn response.

Responses for questions II/1 What type of relationship with others tends to be suggested by the term "friend" and "friendship"?; II/5 How do people usually relate to others of higher or lower social status?; and II/6 To what extent do people tend to feel bound or obligated by their membership in a particular family or clan?, revealed category movements (in each question) for four or more students. The preceding questions will be discussed in more detail in the section entitled, Value Orientation Worksheet - Detailed Analysis. Figures 1 and 2 summarize the detailed analysis which follows. 
Figure 1. A comparison of the category shifts in the post-orientation Russian and American Value Orientation Worksheets.

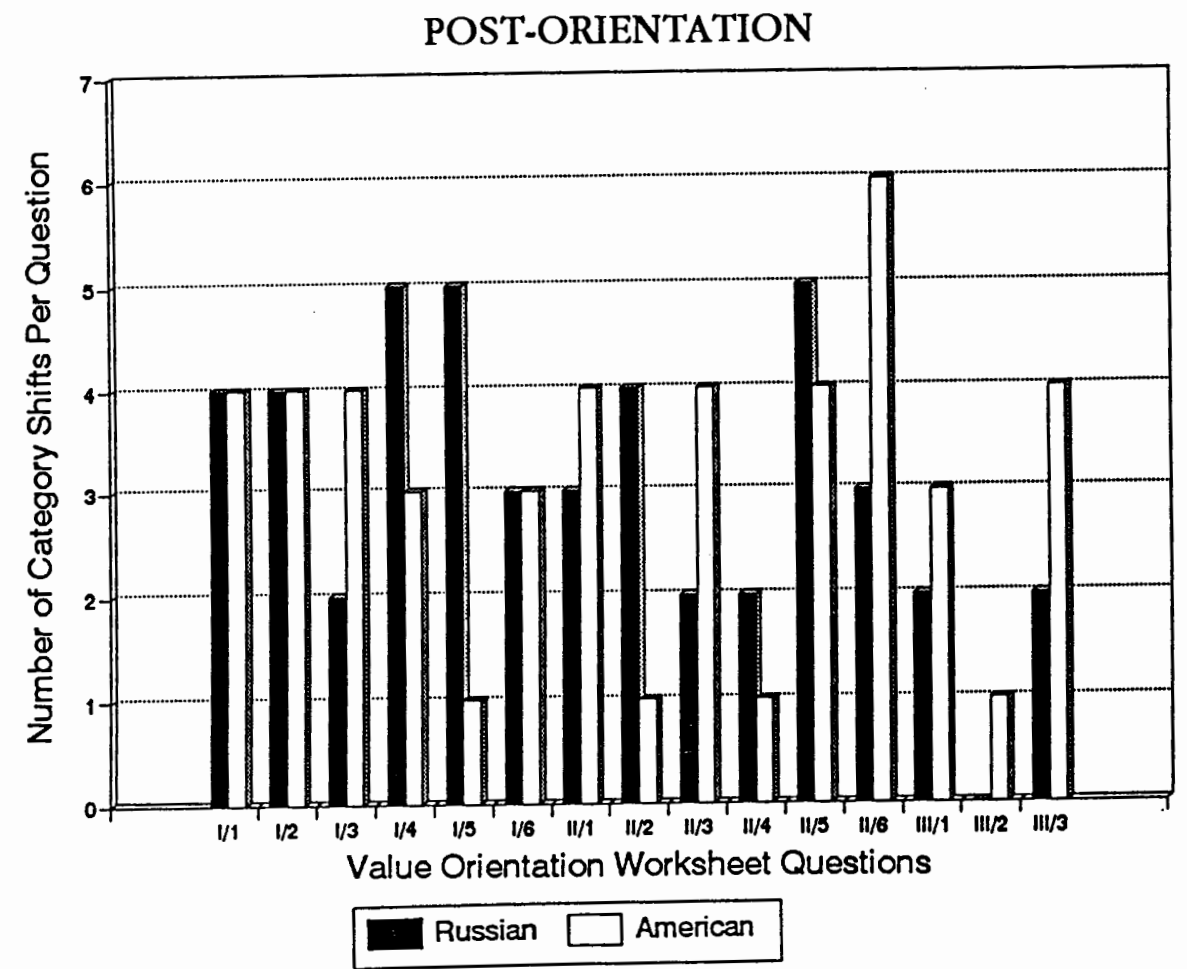

Figure 2. A comparison of the category shifts in the post-sojourn Russian and American Value Orientation Worksheets.

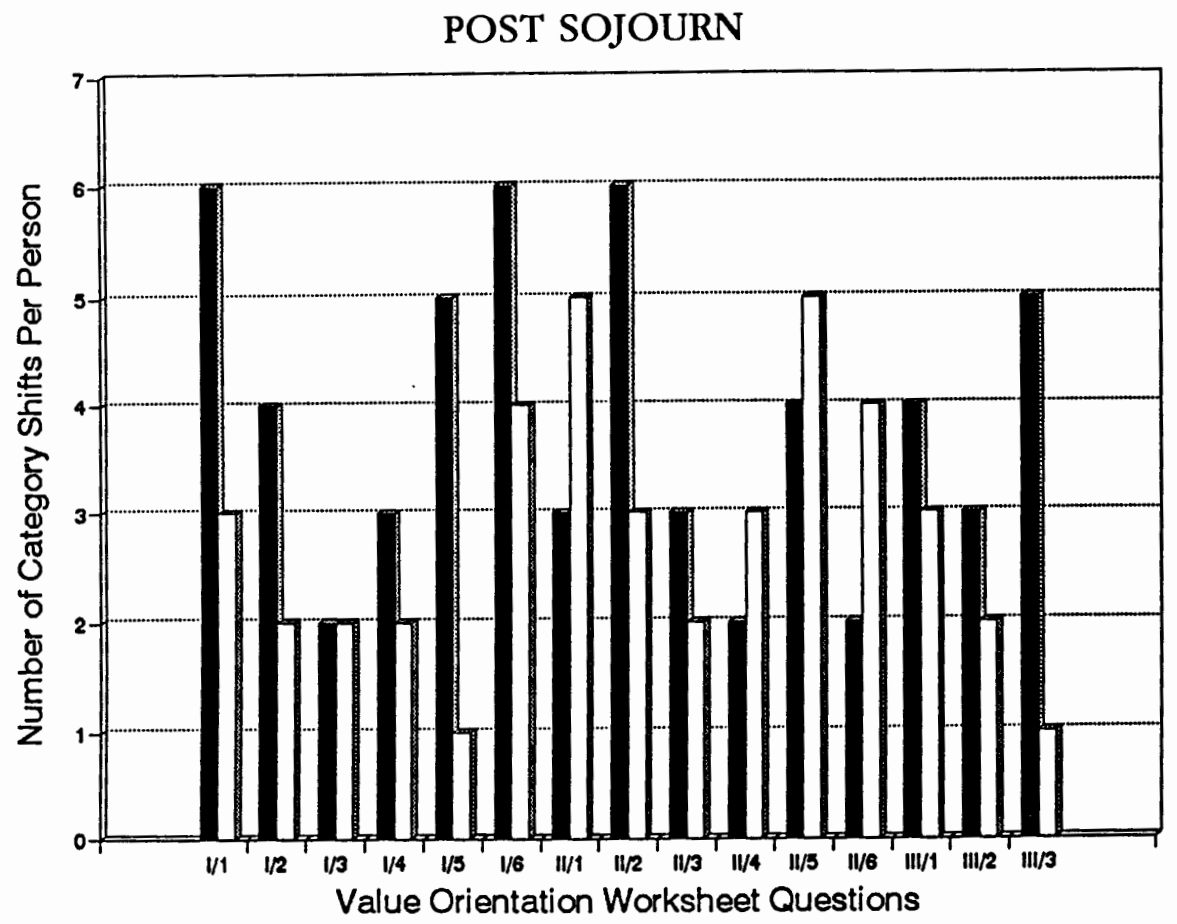




\section{VALUE ORIENTATION WORKSHEET - DETAILED ANALYSIS}

The Value Orientation Worksheets revealed a number of shifts in individual student responses. Every time a student marked his/her response on each question's continuum, he/she was making a choice between three discreet statements. As noted earlier, in comparing pre and post responses, those responses which shifted by .5 or more were considered category shifts as defined by the choices indicated on the continuum. Because of the absence of a control group, it is impossible to ascertain whether or not the shifts observed in the Value orientation Worksheets were a result of either the orientation sessions or the sojourn. It is, however, possible to report the number and direction of the category shifts, to compare the shifts in personal values perceptions versus the perceptions of Russian values as reported on the students' Value Orientation Worksheets, and to look for agreement among the students as to their reported perceptions (for each question) of their own cultural values and their reported perceptions of Russian cultural values.

The Individual

I/1 - American Values. The Value Orientation Worksheet begins with a section related to the individual. The first question $\mathrm{I} / 1$ asks the question: To what extent are people generally assumed to be capable of personal improvement? 1.0 indicates the following response: People are assumed to be capable of enormous personal development and improvement. 2.0: People are 
assumed to be capable of personal growth and improvement to a limited extent. 3.0: People are assumed to be basically incapable of achieving personal growth and improvement.

After the orientation sessions four of the students shifted to the left, into another category, indicating that after the orientation sessions they perceived people to more capable of growth and development than they had indicated on the pre-orientation worksheets.

In comparing the post-orientation responses with the re-entry responses, there were three category shifts. Two to the left and one to the right.

I/1 - Russian Values. The students' pre-departure perceptions of their Russian counterparts in response to question I/1 was somewhat mixed. Preorientation scores ranged from a low of 1.3 (people are assumed to be capable of enormous personal growth and development and improvement) to a high of 2.7 (people are assumed to be basically incapable of achieving personal growth and improvement).

Three of the four post-orientation category shifts were to the left. The range of response was quite similar to that of the pre-orientation worksheets.

Post-sojourn responses revealed category changes for six of the seven respondents. Post-sojourn worksheets indicated that four of the seven students shifted their response to the left to a perception of people are assumed to be capable of limited personal growth and improvement, with two responses indicating a perception of their Russian counterparts as believing people are 
assumed to be capable of enormous personal growth and development. The seventh student stayed constant with a response of people are assumed to be capable of personal growth and development to a limited extent.

I/2 American Values. The second question dealing with the individual relates to the first question, in that it asks another question concerning the individual's role in his/her own future. Question I/2 reads: What do individuals tend to assume about the role of fate in their lives? A response of 1.0 indicates that the respondent believes that: Fate is assumed to bave little or no importance; individuals assume that they are very largely masters of their own destinies and can influence future events. A response of 2.0 states: Fate is assumed to play a moderate role in an individual's life, but the individual is assumed to exercise some control over bis or her own destiny. Scores of 3.0 indicate that the responder perceives fate as playing: a major role in an individual's life; individuals assume that they have little or no control over their own destinies.

Pre-orientation worksheets indicated that the students tended toward the concept of fate assuming a moderate role in an individual's life with the individual assuming some control over their own destiny. Four of the students' post-orientation responses resulted in category shifts, with three of those shifts revealing a belief that fate has a lesser role in their life than previously indicated.

Re-entry responses revealed just two category shifts, both from $2.0-1.5$. 
Three of the students' remained constant at 2.0.

I/2 - Russian Values. The students' pre-orientation responses concerning their perceptions of Russian belief in the role of fate in Russian lives, revealed a variety of responses. Two students perceived of fate as having little or no importance in their lives, three chose a response indicating that fate had little to moderate influence in their lives, and two students perceived fate as assuming a moderate to major role in their lives.

Four of the student's post-orientation responses resulted in a change in categories to the right, indicating a belief that fate plays a greater role in an individual's life than previously thought. Post-sojourn worksheets also revealed four category shifts. In this case however, the shifts were all to the left, back toward an assumption of fate playing a moderate to insignificant role in an individual's life.

$\underline{1 / 3}$ - American Values. Question three in the first section dealing with the individual, focusses on the affect of gender on an individual's roles and responsibilities within the community. Five of the seven shifts from predeparture worksheet \#1 to pre-departure worksheet \#2 were to the right with four of the shifts resulting in a category change. Six of the pre-orientation responses fell between 2.0 and 2.5 with the seventh at 2.7 . Responses in the 2.0 range indicate that the students believe that: being male or female bas moderate power to determine one's roles and responsibilities, but one's interests and abilities are also taken into account. A response of 3.0 indicates 
a perception of: being male or female bas little or nothing to do with the roles and responsibilities that one assumes in the family, among co-workers and friends in society.

Post-orientation worksheet (pre-departure \#2) responses revealed that as in the pre-orientation worksheets, six of the students marked their responses between 2.0 and 2.5. Four of the students shifted into a category different from the one chosen in the pre-orientation worksheets. Two of the shifts were to 2.5 indicating a perception that gender has little to moderate power to determine one's roles and responsibilities. One student moved back to the left, away from gender having little or nothing to do with one's roles and responsibilities, to a position of gender having a moderate influence in determining one's roles and responsibilities. The fourth student shifted to a stronger possibility of gender having little or nothing to do with the roles and responsibilities which one assumes in the family, among friends and in society in general.

The re-entry responses were quite similar to the pre-departure responses. Two the students moved into a different category than previously chosen in the post-orientation worksheets. Both of the shifts were to the left, one from 2.5 2.0, the other from $2.0-1.5$. (The 1.5 was the only score under 2.0 for all three worksheets.) Three of the students remained constant in their scores from the post-orientation worksheet to the re-entry worksheet.

$\underline{I} / 3$ - Russian Values. All but one of the scores in the pre-orientation 
worksheets were below 2.0, and all of them registered at 2.0 or lower in the post-orientation worksheets (pre-departure worksheet \#2). There were two category changes. A score of 1.5 indicates that the students perceive the affect of gender to be between: Distinct and rigidly defined roles and responsibilities are assumed because one is male or female; rarely is there any overlap in expectations of the two sexes; and 2.0 Being male or female bas moderate power to determine one's roles and responsibilities, but one's interests and abilities are also taken into account.

Analysis for the post-sojourn worksheets indicated that there was less agreement among the students than in the pre-departure worksheets.

Responses ranged from 1.0 to 2.5 , with two category changes.

1/4-American Values. What is the most generally approved procedure by which people arrive at conclusions and make decisions? A score of 1.0 indicates respondent believes that: People primarily value subjective factors (such as emotion, personal preference, intuition, or divine guidance) in arriving at decisions and conclusions. 2.0 indicates that the respondent believes that: People strive to be objective in their thinking; they bring together relevant information (facts, statistics, expert opinions, etc.) bearing on the issue, then allow a decision to emerge (inductive reasoning). A mark in the 3.0 range indicates: People strive to be objective in their thinking; they seek general theories or basic principles, bearing on the issue, then arrive at a decision through application of logical thougbt (deductive reasoning). 
The pre-orientation worksheet responses ranged from a low of 2.0 to a high of 2.4. Five of the seven students marked a 2.0. This is one of the smallest ranges of response for any of the pre-departure questions. The postorientation worksheets, however, ranged from $1.5-2.7$. There were three category shifts.

Re-entry responses concerning the manner in which people arrive at conclusions and make decisions revealed little overall change. There were two category shifts. The two category shifts occurred in the worksheets of the two individuals who had the highest scores $(2.5 \& 2.7)$ in their responses on the reentry worksheets. The 2.7 respondent moved to 1.8 and the 2.5 to 1.5 .

I/4 - Russian Values. The pre-orientation worksheets, concerning Russian values, indicated a greater degree of difference than did the American value orientation worksheets. The scores ranged from $1.3-2.5$ for the preorientation worksheets, and from $1.5-2.9$ for the post-orientation worksheets. While five of the seven students' worksheets revealed category shifts, the shifts were not consistent. Three of the shifts occurred in a downward direction, while three of the shifts occurred in an upward direction.

In the post-sojourn worksheets, five of the seven respondents' were between 1.7 and 2.3 indicating that the majority of the students' reported perception of their Russian counterparts was: People strive to be objective in their thinking; they bring together relevant information (facts, statistics, expert opinions, etc.) bearing on the issue, then allow a decision to emerge 
(inductive reasoning). Although there were five responses between 1.7 and 2.3, there were only three category shifts. Two of the students post-sojourn responses mirrored their post-orientation responses.

I/5 - American Values. This question asks; What is primarily valued and respected in individuals? Answer choices are: 1.0 Most valued are the skills they've learned and their individual achievements in life. 2.0 Most valued is their family background in terms of membership in or descent from a certain family. 3.0 Most valued is the depth of their relationship to a Supreme being or commitment to a philosophic ideal.

Pre-departure worksheet \#1 shows a range of 1.1 - 2.6. Post-orientation (pre-departure worksheet \#2) scores range from $1.1-2.2$, with one category shift. Five of the scores were between 1.1 and 1.3. A score in this range indicates a choice of: most valued are the skills they've learned and their individual acbievement in life. Post-sojourn worksheets also revealed just one category shift, with a range of $1.0-2.0$ (six of the students responded between $1.0-1.5)$.

I/5 - Russian values. The students' perceptions of a Russian concept of what is valued and respected in individuals was a different story altogether. Pre-orientation perceptions of what Russians' believe, in respect to what is primarily valued and respected in individuals, were varied. Two of the students marked skills and individual achievements as being most valued. Another two students indicated that they believe that their Russian hosts valued both 
individual skills and achievements and membership or descent from a certain family. The fifth and sixth students chose family background (in terms of descent from a certain family, and the seventh student went with family background coupled with depth of relationship to a Supreme Being or philosophic ideal. (If I were guessing, I would have predicted that the students would fall heavily on the far right - commitment to a philosophic ideal.

Perhaps this is a difference in perception influenced by my being a member of the generation which experienced the cold war and the build-up of nuclear arms against a perceived Soviet threat.)

Post-orientation responses revealed a range of 1.5 to 2.5 . Five of the seven responses were between 2.0 and 2.5. There were five category shifts, all to the right. Two of the students moved to a perception that both individual skills and family background are highly valued (1.5), two to most valued is family background (2.0), and two to mid-way between family background and depth of relationship to a Supreme being or commitment to a philosophic ideal (2.5). (The seventh student remained constant at the 2.5 mark.

Analysis of the re-entry worksheets revealed a consistent shift in student response to a perception that their Russian counterparts value and respect, botb an individuals' learned skills, and their membership in or descent from a particular family. Six of the seven students' responded with a 1.5 while the seventh marked the continuum at 1.7. This was the most cohesive response of any question across all six worksheets. 
$\underline{1} / 6$ - American Values. On what basis do most people judge procedures, events, and ideas? Participant response for both pre-departure worksheets indicated that the students' perceive that: Judgements are most often made on the basis of ethical considerations (by asking, "is it right? Is it just? Is it good?). There were no marks above 2.0 , indicating that none of the students' perceived that: Judgements are made on the basis of congruence with tradition (by asking, "is it similar to the ways preferred by our ancestors?). The third choice was at the 1.0 mark which states: Judgements are most often made on the practical considerations (by asking, "Does it accomplisb a needed task? Does it work well?"). Post-orientation responses revealed three category changes.

The re-entry worksheets revealed very similar responses to those of the pre-departure orientation worksheets. Responses ranged from 1.0 - 1.8. Six of the seven students responded between 1.5 and 1.8. There were four category shifts in the post-sojourn worksheets.

1/6 - Russian values. Scores for the students' perceptions of the manner in which their Russian counterparts most often judge procedures, events, and ideas were all over the scale, ranging from $1.2 \cdot 2.8$ on the pre-orientation worksheets, and from $1.3 \cdot 2.8$ on the post-orientation worksheets.

Post-orientation worksheets revealed that three students shifted categories, two to the right and one to the left. Analysis of the post-sojourn worksheets reveal shifts in all of the respondents with six of those shifts 
resulting in category changes. Although there was a large number of category shifts, the shifts did not all move toward the same point. The range in responses was $1.0 \cdot 2.5$, quite similar to that of the two pre-departure worksheets.

\section{Social Relationships}

II/1, II/4, \& II/6 - American Values. This group of questions relates to family obligations, friends, and group affiliations. Question II/1 states: What type of relationship with otbers tends to be suggested by the terms "friends" and "friendship? Question II/4 reads: To what degree do people tend to remain loyal to groups and organizations?; and question II/6 states: To wbat extent do people tend to feel bound or obligated by their membership in a particular group or clan?

II/6 - American Values. The students' responses to the question concerning ties and obligations because of family or clan membership (II/6), were quite varied. Pre-orientation worksheets revealed responses varying from 1.0 to 2.4 , while post-orientation worksheets revealed a range of responses from 1.4 to 2.7. Worksheets for all seven students' showed movement with six of the moves resulting in category changes. There was only one response above 2.5 , indicating that only one student perceived of family membership as involving numerous binding obligations. The remainder of the students were scattered between family membership involves few binding obligations and some binding obligations. 
Post sojourn responses for question II/6 were, like the pre-departure worksheets, quite varied. Responses ranged from 1.3 to 3.0 - covering all possibilities. There were four category shifts, two to the right (family membership involves numerous binding lifetime obligations) and two to the left (few to some binding family obligations). This question evoked a wider range of response across all three worksheets than any other question.

Question II/1 -American Values. This question which asks: what type of friendship with others tends to be suggested by the terms "friend" and "friendship?, indicates a much higher degree of agreement than question II/6, which questions a broader range of relationships and obligations. The range of responses on the pre-orientation worksheet varied from 1.2 - 2.7. Postorientation responses ranged from 1.8 to 2.4 .

All of the students who responded with a 2.0 or higher on the preorientation worksheets, moved to the left - or back toward the center. Those students whose responses were the lowest $(1.2 \& 1.3)$ moved to just above the mid-point $(2.4 \& 2.3)$ on the post-orientation worksheets. That movement put all participant responses firmly in the center of the scale indicating that they perceive their relationship with friends as: moderately intense and intimate and may last for short or long periods; mutual obligations are moderate in scope and depth; a person has a modest number of friends.

Re-entry responses fell between $1.5 \& 2.6$. There were two responses tending to more intense, intimate friendships, and one leaning toward 
friendships as being comparatively superficial. The students were not consistent with their individual responses across the three worksheets, nor were they consistent as a group. Post-orientation responses revealed four category changes, with three of those students changing category responses once again on the post-sojourn worksheets. A total of five students shifted into a different category after the sojourn. Two of the shifts indicated a response which allowed for both intimate, longlasting friendships and moderately intense friendships which may last either for short or long periods of time. The other three shifts were in the opposite direction indicating that friendships can be both moderately intense for a varied amount of time, or they are comparatively superficial, often depending on overlapping interests.

II/4 - American Values. Scores to question II/4: To what extent do people tend to remain loyal to groups and organizations? indicates response patterns very similar to those of friendship and family/clan obligations discussed above. The students' tended to perceive that most people feel a strong sense of loyalty to some organizations, but for others will remain members only as long as their membership or employment fulfills their personal goals. There were two exceptions to this "norm." (1.) The student who felt that once people joined an organization, they remained deeply loyal even if their personal goals remained unfulfilled. (This student saw friendship as moderately intense, lasting for long or short periods, with moderate obligations and a modest number of friends. He/she had the lowest score in relationship to his/her 
concept of family, perceiving binding family obligations as few with the coming of age freeing him/her to pursue his/her own interests with relatively little direct support from family members.) (2.) The other student who deviated from the majority, did so only in the area of family obligations (question II/6). This student reportedly perceives of family obligations as being numerous and binding throughout one's life. With these obligations however comes a lifetime of family support in the form of aid, comfort and advice.

The post-sojourn responses for question II/4 placed the students as feeling both a strong sense of loyalty to some organizations while also moving easily from organization to organization. Scores ranged from $2.0-2.7$. The student who responded with a strong sense of loyalty to an organization $(1.4 \&$ 1.2) on the two pre-departure worksheets shifted to a 2.5 on the re-entry worksheet; choosing an option of feeling both a strong sense of loyalty to an organization, and ease of movement between organizations depending on whether personal needs are being fulfilled. There was one category shift in the post-orientation worksheets and three in the post-sojourn worksheets.

II/1, II/4, II/6 - Russian values. Question II/1 asks: What type of relationship with others tends to be suggested by the terms "friend" and "friendsbip"? In contrast to the students' perceptions of their own American values, they perceived their Russian counterparts as having a few, intense, long lasting, intimate friendships, involving numerous mutual obligations which are keenly felt and unlimited in scope. Five of the pre-orientation responses were 
1.5 or under with the other two recording a 1.7 and a 2.0 .

Post-orientation responses revealed a similar spread with responses ranging from $1.3-2.0$. There were three category shifts, two to a perception of the relationship with friends as intense and long lasting, and one to more moderately intense friendships.

Two of the students who changed category responses after the orientation sessions also changed categories after the sojourn. One moved back toward his/her pre-orientation choice - to a perception of friendships being very intense with long term obligations, and the other to a perception of Russian friendships as being only moderately intense with the possibilities of being either long or short-term relationships. The third person, whose postsojourn worksheet revealed a category shift, moved from a position midway between intense and moderate friendships to one midway between moderate and superficial.

II/4 -Russian Values. In the area of loyalty to groups and organizations, the students again perceived their Russian counterparts as having a deeper loyalty to an organization then would be expected from an American.

The range of response for the pre-orientation worksheets was $1.3-2.5$ with the most frequent response of 1.5 occurring in three instances (five of the students were between 1.3 and 1.5). Post-orientation worksheet responses ranged from $1.0-1.8$, with three responses 1.3 and under and three between 1.6 - 1.8. There were just two category changes in the both the post- 
orientation and post-sojourn worksheets for this question.

II/6-Russian Values. Question II/6 asks: To what extent do people tend to feel bound or obligated by their membership in a particular clan or group? Pre-departure responses to this question again indicated a perception by the students that Russians' feel more obligation to their family then do the American students. Pre-orientation responses ranged from 1.8 -3.0. Postorientation responses revealed three category shifts with the range of response moving closer together. (Post-orientation responses ranged from 2.4 - 2.9.)

Post-orientation responses indicated that the students' perceived that for their Russian counterparts, membership in a family involves a great number of obligations that may continue unabated throughout one's lifetime. However, with this stronger tie comes the promise of ever present aid, comfort and advice.

The apparent move toward consensus concerning the students' reported perception of a Russians' sense of obligation to a particular family or clan as revealed in the tighter post-orientation responses, was not replicated in the post-sojourn responses. Instead, post-sojourn responses looked very much like the pre-orientation responses with a range in response from $1.7 \cdot 3.0$. There were two category shifts both to the left to a 2.0 .

I1/2 - American Values. How are personal disagreements and conflicts usually dealt with? The three choices the student's were given to answer this question were: 1.0 - Conflicts and disagreements are ignored, played down, or 
suppressed so that they are very rarely dealt with openly or directly; 2.0 Intermediaries (go-betweens) such as mutual friends are very often used by people in their efforts to resolve conflicts and disagreements; 3.0 - People in conflict with each other often attempt to work out their differences in face-toface discussion or other contact with each other.

Five of the students' marked their pre-orientation worksheets between 2.5 and 2.7. The other two students responded with a 2.1 and a 1.9. A response at 2.5 indicated that the students use both intermediaries and face-toface discussion in working our differences and dealing with conflict.

Post-orientation responses revealed one category shift. Post-orientation responses ranged from $1.6 \cdot 2.9$. Four students marked a 2.5. Analysis of the post-sojourn worksheets revealed a response range of $1.5-2.5$. Four of the responses were between 1.8 and 2.2 , indicating a tendency away from the equal use of intermediaries and face-to-face discussion toward the use of intermediaries in the solving of disagreement and conflict. Three students changed categories in the post-sojourn worksheets. All of the category shifts were to the left.

II/2 - Russian Values. Unlike the high degree of agreement among the students in relation to their perception of their own cultural values concerning personal disagreements and conflict, there was little agreement among the students concerning how a Russian would solve a personal conflict.

Pre-orientation responses ranged from $1.6-2.8$. Post-orientation 
responses ranged from $1.4-2.0$. A comparison of individual student scores, for the pre-departure worksheets, indicated that their pre-orientation perceptions of a Russians' response to personal disagreement and conflict, was very close to their own beliefs, (using either intermediaries or face-to-face discussion in handling conflict), while post-orientation responses indicate a shift to the use of intermediaries (two responses) or a combination of playing down or suppressing disagreements and conflict and the use of intermediaries (four responses). (One student stood alone with a movement of 1.6 to 1.4 to 2.8 .)

Post-sojourn responses revealed that six of the students changed categories. The shifts, however, were not consistent (five moved to the right two to the use of both intermediaries and face to face discussion, two to the use of intermediaries, and one to face to face discussion).

It is the opinion of the researcher that the question of the manner in which disagreements and conflict are resolved is one which would benefit from further study. Interpersonal communication can be greatly enhanced if all participants are interacting from either a common value system or an understanding of their cultural value differences.

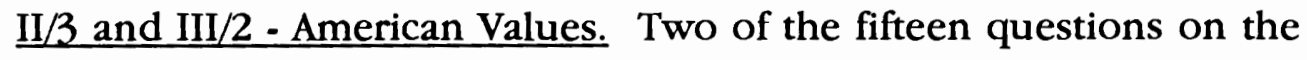
Value Orientation Worksheet deal with the issue of time. The first question (II/3) asks: What is the primary orientation of people with respect to time? Pre-departure worksheet \#1 shows a much wider range of responses than I anticipated. Responses ranged from a 1.2: The past is of primary interest and 
importance, to a 2.7: The future is of primary interest and importance. (A score of 1.0 indicates the past is of primary importance, 2.0 - the present is of primary importance, and 3.0 - the future is of primary importance.)

In the post-orientation worksheet, the responses were much tighter, ranging from a low of 2.0 to a high of 2.7. There were four category shifts. All but one of the respondents moved right or stayed constant. The individual who moved left was the 2.7 respondent who moved closer to the mid-point at 2.2.

Post sojourn responses were as varied as the pre-orientation responses. Two of the students' responses revealed category shifts. Clearly the students, although manifesting many similarities, are not a homogeneous group with respect to their orientation to time. It would be interesting to study this issue further perhaps looking at other time related questions as well as asking about long and short range goals.

The second question concerning time (question III/2) asks: How does time tend to be defined and valued? Pre-orientation responses ranged from 1.0 - 2.2. Five of the responses were between 1.0 and 1.2 indicating a response of: The passage of time is keenly sensed; because its passage is thought to occur very rapidly, time is valued as a limited resource that ought to be "saved" whenever possible and not be wasted. The tight range of response for these five students indicates a strongly held value.

Post-orientation responses closely mirrored the pre-orientation 
responses. The five students who were between 1.0 and 1.2 remained constant, while the individual who had responded with a pre-orientation mark of 2.1 shifted to a 2.8 and the individual with a pre-orientation 2.2 moved the opposite direction to a post-orientation 1.8 .

Post-sojourn worksheets indicated that the majority of the students' continue to define and value time as a limited resource that ought to be "saved" whenever possible and not wasted. Six of the students' responses fell between 1.0 and 1.5. (The individual who responded on the post-orientation worksheet with a 2.8 shifted back to the left to a 1.0.) One student however remained constant through all three worksheets with a response of: There is little or no consciousness of the passage of time, except perbaps in terms of the changing seasons; to the extent that time is sensed at all, it is thought of as occurring in big chunks.

II/3 \& III/2 Russian Values. Pre and post-orientation worksheets suggest that the students' perceive their Russian counterparts to be present oriented in respect to time, as indicated in their responses to question $I I / 3$.

On the post-sojourn worksheets the students continued to think of their Russian counterparts as being primarily present oriented. Scores ranged from $1.5-2.3$ with five of the responses falling between 1.8 and 2.0. The student who responded with a strong post-orientation future orientation, moved to an equally strong present orientation after the sojourn. (There were two postorientation category changes, and three post-sojourn category changes.) 
III/2 - Russian Values. For the second question relating to how time is defined and valued (III/2), all seven of the students responded on the preorientation worksheet between 1.5 and 2.0. Post-orientation responses indicated little change, with scores ranging from 1.4 to 2.0. There were no category shifts. Post sojourn responses revealed three category shifts. Scores ranged from 1.0 to 2.5 with five of the seven responses between 1.5 and 2.0.

II/5 - American Values. How do people usually relate to others of bigher or lower status? Options for this question ranged from: 1.0 - Although people are aware of differences in social status, they ignore or play down such differences in almost all their relationships with others; informality prevails almost all the time; 2.0 - social status differences are moderately important in social relationships; in a few situations, very formal or ritualized bebavior is observed when higher or lower status people meet; 3.0 - Social differences carry great weight in almost all social relationships; in most social situations formality or ritual governs behavior when higher and lower status people are together.

Pre-orientation scores ranged from $1.3-2.3$, with five of the responses between 1.8 and 2.3. Responses in this range indicate that the majority of students' believe that social status is moderately important in social relationships.

Post-orientation scores ranged from $1.2-2.5$. While four of the students' worksheets revealed category changes, they did not move uniformly. Three of 
the students shifted to a position that one's social status has a small to moderate affect on social relationships, while the fourth student moved in the opposite direction to social status carrying moderate to great weight in social relationships.

Post-sojourn responses indicated that the post-orientation shifts did not remain constant. Scores ranged from $1.0 \cdot 2.3$, with five of the students choosing a different category from the one chosen in the post-orientation worksheet. Although the range is strikingly similar across the three worksheets, the individual responses varied from worksheet to worksheet.

II/5 - Russian Values. How do people usually relate to others of bigher or lower status? Pre-orientation responses ranged from $1.4-2.7$, with responses in all possible categories. Post-orientation responses revealed five category changes. The two students whose post-orientation responses did not result in a category change were the two who responded with a 2.7 on the preorientation worksheets.

Even though there was a large amount of movement on this question, the students' responses were consistent, in that, in comparing individual responses for American and Russian values, five of the seven post-orientation responses were higher on the Russian Values Orientation Worksheet. The higher numbers indicate that the students' perceive their Russian counterparts as giving more weight to status in social relationships then they do in their own social relationships. 
Post-sojourn responses indicated that the post-orientation responses did not remain constant. There were four category shifts, but the responses were not in agreement. Post-sojourn worksheets revealed a slightly greater range of response than either of the two pre-departure worksheets. Responses ranged from $1.0-2.8$. The 1.0 response was from one of the students who had remained constant at 2.7 in the pre-departure worksheets. The other response of 2.7 shifted to a 2.5 .

\section{Nature and the Supernatural}

III/1 - American Values. How does the interaction between bumans and nature tend to be conceived? On the pre-orientation worksheet (pre-departure worksheet \#1), three of the students responded between 1.2 and 1.4 . 1.0 states: Humans are conceived as baving the right to attempt to control the natural world and to exploit it for their benefit and progress. The other four students responded with scores from $1.7-2.2$. The statement for 2.0 reads: Humans are conceived as baving an obligation to live in ecological balance with nature, or as being an integral part of nature designed to live in barmony with all other parts. 3.0 states: Humans are conceived as being subordinate to nature, and as being powerless in the face of overwbelming natural forces that remain beyond tbeir control.

Post-orientation responses ranged from $1.2-2.0$. There were three category shifts. Post-sojourn responses revealed that all of the students fell between perceiving humans as having both a right to attempt to control the 
natural world and an obligation to live in ecological balance with nature.

Responses ranged from $1.0-2.0$, with five of the seven responses between 1.5 and 2.0. One of the students wrote on his worksheet that while he felt that [American] society believes that they have the right to control and exploit the natural world, society is moving toward living in ecological balance with nature.

III/1 - Russian Values. The range of responses for the pre-orientation worksheets ranged from $1.4-2.5$, with five of the seven responses between 1.8 and 2.2. The responses between 1.8 and 2.2 indicate a response of; bumans are conceived as having an obligation to live in ecological balance with nature, or as an integral part of nature destined to live in barmony with all other parts.

Post-orientation scores fell between $1.7 \cdot 2.6$. There were two category changes. The responses at 2.6 indicate that the students' perceive their Russian counterparts as conceiving of humans as having an obligation to live in ecological balance with nature while also being both subordinate to nature, and powerless in the face of overwhelming forces that will always remain beyond their control.

Post-sojourn worksheets indicated that six of the seven students shifted back to the left with the seventh remaining constant at 2.0. Those shifts brought all seven students back to a perception of their Russian counterparts as conceiving of the interaction between humans and nature as; Humans are conceived as having an obligation to live in ecological balance with nature, 
or as being an integral part of nature destined to live in barmony with all other parts.

III/3 - American Values. $111 / 3$ reads: To what extent are material things and the fruits of buman progress assumed to be available to buman beings? Pre-orientation responses ranged from $1.4-2.5$. Four of the students indicated a response of; Material things and the fruits of buman progress are assumed to exist in moderately abundant supply, so that only some people can enjoy them; those who are most able and who work the bardest can bope to gain bappiness and well-being. One student leaned toward a more limited supply of material things (the response of 1.4 ), while two students were between material things and the fruits of progress existing in a moderate to unlimited supply (2.5)

Four students' responses indicated movement which resulted in a category change. The student who responded with the 1.4 on the preorientation worksheet, shifted to a post-orientation high response of 2.7 , indicating a belief that material things and the fruits of human progress are thought to exist in a virtually unlimited supply. 'The other six students' responses ranged from $2.0-2.5$, four of the students marked a 2.0 . 2.0 reads; material things and the fruits of buman progress are assumed to exist in moderately abundant supply, so that only some people can enjoy them; tbose who are most able and who work the bardest can bope to gain bappiness and well-being. 
Post sojourn responses revealed that three of the students remained constant at 2.0 while the other four ranged in response from $1.8-2.5$. There was only one category shift.

III/3 - Russian Values. The pre-orientation perceptions of the students concerning a Russian's concept of the availability of material things and the fruits of human progress was somewhat more limited, indicating that the students' perceive of their Russian counterparts as somewhere between assuming that there is a strictly limited supply of material things and a moderately abundant supply with the possibility that hard work will bring some sense of happiness and well-being. Pre-orientation responses ranged from 1.4 2.0. Five of the responses were between 1.4 and 1.5 .

The statement for 1.0 reads: Material tbings and the fruits of buman progress are assumed to exist in strictly limited supply, so that only a few people can enjoy them; most people are destined to sadness and poverty tbroughout their lives, and there is notbing they can do to change their condition. 2.0 reads; Material things and the fruits of progress are assumed to exist in moderately abundant supply, so that only some people can enjoy them; those who are the most able and who work the bardest can bope to gain bappiness and well being. On the opposite end at 3.0 the statement is: Material things and the fruits of progress are assumed to exist, at least potentially in virtually unlimited supply, so that almost everyone can enjoy the; happiness and well-being can be attained by all wbo strive to gain them. 
None of the scores in the pre-orientation worksheet were above 2.0 , while the high for the post-orientation worksheet was 1.7. Post-sojourn responses again appear to indicate that the students' perceptions of how their Russian hosts' perceive of the extent to which material things and the fruits of buman progress are available to buman beings, was more limited than their own perceptions. Responses ranged from $1.2-2.5$. It is interesting to note however, that in comparing the students' individual scores for themselves and their Russian counterparts, three of the students scored their own American values worksheets lower (with a more limited assumption) than the Russian worksheets, two higher, and one the same. There were five category changes.

\section{SUMMARY}

The hypotheses statements at the beginning of this chapter state:

1. There will be observable shifts in the individual student's reported perceptions of Russian values after the five pre-departure orientation sessions. (Value Orientation Worksheet pre-departure \#1, and Value Orientation Worksheet pre-departure \#2). Post-orientation responses revealed observable shifts in all of the fifteen questions.

2. There will be observable shifts in the individual student's reported perceptions of Russian Values following their sojourn in Russia, Value Orientation Worksheet pre-departure \#2, compared with Value Orientation Worksheet \#3 - re-entry.) As in the first hypothesis there were observable shifts 
in all of the questions.

3. There will be observable changes in the personal values orientation worksheets of the students, (Value Orientation Worksheet pre-departure \#1 compared with pre-departure \#2, and pre-departure \#2 compared with \#3 reentry.) Analysis of the students' personal Value Orientation Worksheets revealed that there were observable shifts in both the post orientation worksheets and in the post sojourn worksheets.

In conclusion, it appears to the researcher that the orientation sessions had a greater impact on the students' reported perceptions of their own cultural values than in changing their reported perceptions of Russian values. Whereas there were five areas in which the majority of students changed their reported perceptions of their own values, there were only two areas which revealed category changes in regard to the students' reported perceptions of Russian cultural values. Although the orientation sessions were designed to give the students' some understanding of Russian culture - until they experienced Russia for themselves, the information appears to have been just a another set of facts surrounded by hard to pronounce Russian names and places. In the words of fourth century B.C. Chinese poet Chung Tzu:

How shall I talk of the sea to the frog, If he has never left his pond?

How shall I talk of the frost to the bird of the summerland If he has never left the land of his birth?

How shall I talk of life with the sage, If he is a prisoner of his doctrine? 
shifts in the students' perceptions of their own cultural values and their perceptions of Russian cultural values. 


\section{CHAPTER VII}

\section{DISCUSSION}

It was suggested in the introduction to this study that previous research dealing with the affects of a travel abroad program on the young people involved was mixed. While most of the researchers were able to identify some changes which occurred as a result of the sojourn, other factors were frequently involved. This study is no exception. There were as hypothesized, observable shifts after the pre-departure orientation as well as after the sojourn. The preceding sections gave a detailed analysis of each question across the six Value Orientation Worksheets.

Whether participating in a large group or a small group, there are significant factors which influence a student's experience abroad. These factors include; the age and gender of the sojourners; the length of the sojourn, the activities of the sojourner while in the host country, and the attitudes and perceptions of the sojourner previous to the sojourn. Like the previous studies spoken of in the body of his paper, these same factors can also be considered to be significant variables in the study at hand.

The age of the sojourners was discussed previously in regard to their orientation to time. Was their time orientation a reflection of fast approaching life changes, such as leaving home for college, entering a new high school or 
recognizing that this was their last year in high school - all realities for one or more of the students. A larger sample size coupled with related questions relating to time might provide a better framework for answering this question.

The experience of the lone male in the group (outside of the adult male coach) can not be measured with any accuracy in relation to the influence of gender on the sojourn experience. The issue of how males respond differently from females in a short-term sojourn experience is a question which will need further research.

In his research concerning the affects of a short trip abroad on groups of tourists, Pearce (1988) found that attitudinal changes occurred as a consequence of day-to-day encounters with the locals. In this study, the students, like the tourists in Pearce's (1988) study, were in the host country for a short period of time. Unlike the tourists in Pearce's study the students joined together for five pre-departure orientation sessions. As detailed in the preceding section, while there were more category shifts after the orientation sessions in relation to their own cultural values, their reported perceptions of Russian cultural values was relatively unchanged.

As with Pearce's (1988) study it is difficult to quantify the affect of the day-to-day interaction. Did the constant and close encounters with Russians of all ages account for the observable changes in perceptions revealed in the post sojourn responses, or were the attitudes and experiences which the sojourners' took into Russia with them an overriding influence on any change or lack 
thereof? The information obtained in this study is inadequate to answer these questions.

In addition to the factors identified by Hansel (1984) as potentially making a significant difference in the sojourn experience, the size and orientation of the group are also factors worthy of consideration. If the group had been larger it is very possible that the sojourn would have been a different experience altogether. Being a group of only seven, the students had a high level of contact on a daily basis. Everywhere they went they were greeted by large groups of children calling "Amerikanski", and pressing into their hands small commemorative pins. Indeed, after a few days the students began to tire of their celebrity status, wishing they could sink into quiet anonymity.

Comments frequently heard among the students at the re-entry party, while viewing their Russian slides and sharing their photo albums, ran along the lines of; "my gosh, remember how all we wanted to do in the sports camp was stay in our cabins and play cards?"

On the other hand, being a part of a very small group allowed for more intimate and personal contacts than are possible in very large groups. The students were able to meet extended family members, join in local festivities, and grow to know and appreciate their Russian host guides and interpreters, as evidenced by the hugs and smiles when the Russian exchange group traveled to Portland ten months later.

What about the composition of the group? Was the fact that all of the 
students were athletes, who had travelled to Russia to train and compete with Russian athletes, a factor in the sojourn experience? Was the sojourn experience affected by the competitive nature of the athletes? Would another group, travelling as non-athletes, have responded similarly? These are questions which cannot be answered with the information at hand but are, I believe, valid questions which could very well be considered significant variables in future research.

\section{SYNTHESIS}

What does all of this mean? As I began to integrate the literature review and my research findings I was reminded of the Russian proverb "Don't hurry to reply, but hurry to listen." What does this study tell us about perception and cultural value orientations in the context of an Intercultural sojourn? According to Brunner (1958) we all construct frames of reference which give structure and meaning to that which we experience. Our cultural belief system, our role in society and our life experience become the foundation to this preconceived framework. If we are to make sense of another individual's actions and beliefs, we must try to understand their perceptual frames of reference.

In the literature review, Russian and American cultural values were discussed as a backdrop for understanding the culture influences on the sojourner's perceptual frames of reference, as well as on what they might expect to find in the perceptual frames of reference of their Russian hosts. The 
following section will look at the extent to which the findings reflect the literature.

As noted earlier, Pearce (1982) documented two opposing views of the effects of the travel experience on the travelers themselves. The first as espoused by Huxley (1925) states: "we travel not that we may broaden and enrich our minds, but that we may pleasantly forget that they exist" (p. 18). The opposing view concludes that even those participating in a short two-tothree week tour are likely to both alter their views of the host country and return home with a different perspective of their own culture.

Huxley's viewpoint concludes that the tourist experience is shallow and inconsequential with little lasting effect on the traveller. The Value Orientation Worksheets taken nine months after the sojourners returned home suggests that the sojourners in this study, rather than resembling Huxley's tourist, were instead much like the tourists in Pearce's 1988 study who both modified their perceptions of their hosts, and re-appraised aspects of their own cultural values.

The following section will look at specific areas in which the students; (1) modified their reported perceptions of their own cultural values and/or those of their Russian hosts, or (2) reported perceptions of American or Russian cultural values which are at variance with the findings in the literature review.

One of the major socio-cultural elements which according to Porter and Samovar (1988) directly influences our perceptions and the meanings we develop for them is that of our world view. World view issues endure through 
time, influencing culture at a deep and often subtle level. Included in a culture's world view are such things as humanity, and man's relation to God and the universe. Porter and Samovar (1988) go on to state that world view is so deeply embedded in our psyche that it is often taken completely for granted.

A review of the literature in relation to Russian and American values concerning world view in the area of "man" - nature revealed that Americans see a clear separation between man and nature, with man the master of his own destiny. Americans believe that they can subdue, dominate and control the natural environment (Kohls, 1984). Russians, according to Custine (1839), Richmond (1992) and Willis (1985) are much more likely to believe that man is in a perpetual struggle with a rebellious nature, and are driven and controlled by Fate.

It is with these statements in mind that we look at the students' responses to question III/1 which asks: How does the interaction between bumans and nature tend to be conceived? Post-sojourn responses on the American values worksheets revealed that the students' reportedly perceive that while humans have a right to attempt to control the natural world, exploiting it for their own benefit and progress, they have a greater obligation to live in ecological balance with nature. The students' responses suggest that the American belief that man can subdue, dominate and control the environment as reported by Kohls (1984), for these students at least, has perhaps been tempered by the realities of the last decade as environmental issues have risen 
to the forefront around the world.

A comparison of the student's post-sojourn responses on the Value Orientation Worksheets - American Values with their responses for this question on their Value Orientation Worksheets - Russian values, revealed that five of the seven students chose the same category on the Russian values worksheet that they chose for themselves (on the American values worksheet). Were the students observing a shift in the perception of man's relationship to nature in Russian culture, or did they form their perception on their personal cultural background and life experience? Further research needs to be conducted to answer this question, the implications, however, are far reaching as we deal with the vast environmental and ecological issues of the twentieth century. A related question is that of $1 / 2$ What do individuals tend to assume about the role of fate (chance) in their lives? When considering the role of fate in one's life, the subject of optimism is never far behind. Russians expect life to be hard and things to go poorly. Russians are suspicious of the "smiling" Americans and consider the eternal American optimism which sees a "pot of gold at the end of every rainbow" to be naive. According to a Russian proverb "if men could foresee the future, they would still believe as they do now" (Richmond, 1992, p.65). "A Russian joke describes a Russian pessimist as a realistic optimist" (Richmond, 1992. p. 41). When asked how things are, the likely reply is normalno (normal) which can be translated either "not too bad", or in the words of translators Richard Lourie and Aleski Mikhalev, normalno is a 
"wistful, ironic word, containing all the pain that came before and all of the hope of what might yet come to pass, the great dream of the present, a 'normal' society" (Richmond, 1992, p. 41).

Feeling much less in control of their lives than the individualistic American, "Russians feel caught up in the big sweeps of history where the individual does not count....According to Lourie and Mikhalev the difference is simple and dramatic:

For us, history is a subject, a black-and-white newsreel; for them it is a tank on their street, a search of their apartment by strangers with power. In the Soviet Union nearly every life has been touched directly, branded by the great historical spasms of revolution, war and terror...(Richmond, 1992, p.43).

The students' post-sojourn responses to question $1 / 2$ regarding the role of fate in one's life revealed that like the previous question regarding man's interaction with nature five of the seven students' responses indicated they perceive that their Russian hosts have an assumption concerning the role of fate in their lives which matches their own. Four of the students responded that they believe that while fate may play a small role in their lives, they are largely masters of their own destiny. The other three responded with an assumption that while fate may play a moderate role in their lives, they exercise some control over their own destiny. Is there a change occurring in Russia regarding the role of fate in one's life? Russians have traditionally been much less mobile than Americans in their ability to choose their occupation and even their place of residence. During the Soviet era in particular, the heavy hand of the 
government was pervasive throughout the economy, culture, education, the media, religion, and in the private lives of Russian citizens - "planning, directing, instructing, and stifling initiative in the process" (Richmond, 1992, p. 68). Richmond (1992) goes on to state that until the free elections of 1991, "democratic government in Russia was experienced only once, in 1917 during the brief period between the democratic February Revolution and the Bolshevik October Revolution" (p. 67).

In speaking of the tendency of people of all cultures to base their understanding of the behavior of others on their own cultural value systems, Schutz (1967) asserts that we must recognize that people in different times and places see the world differently. Did the American students base their responses on their own assumptions concerning the role of fate in one's life, or were the discussions around the dinner table concerning the changes in Russian life since the breakup of the Soviet Union a factor in their responses? Only time and further research will bring the answers to many of the questions regarding what appear to be the small stirrings of change in present day Russia. Although one can look at individual aspects of cultural value systems as exhibited in Chapter III, it has become increasingly evident that there is much overlapping and inter-relation among the values. As noted earlier, Russians live in a society with strong traditional roots in communalism and collectivism, while Americans have a tradition of strong individualism. Americans speak of "one man - one vote." A Russian proverb states; "In a field of wheat, only the 
stalk whose head is empty of grain stands above the rest."

These two aspects of Russian and American culture are also reflected in each nation's form of government. Authority flows downward in Russia. Caution and conservatism have been the guiding principle. According to Richmond (1992) "the tried and tested is preferred over the new and unknown" (p. 39). A Russian proverb says, "The slower you go, the further you'll get" (Richmond, 1992, p. 39). Russians write thirty year plans, while Americans expect each new political candidate to fix the ills of society beget by the generations before them. One hundred and fifty years ago Alexis de Tocqueville wrote:

"America's conquests are made with the plough share, Russia's with the sword....To attain their aim the former relies on personal interest and gives free scope to the unguided strength and common sense of the individual. The latter in a sense concentrates the whole power of society in one man, one has freedom as the principal means of action, the other has servitude...(Tocqueville, 1969, p. 43).

The American individual is also highly activity or "doing" oriented, like the athlete, the latest political candidate is expected to "just do it." Americans define themselves in terms of their activities - what they do. A Russian proverb says "Don"t hurry to reply, hurry to listen." Russians are more prone to a being or thinking orientation. Condon \& Yousef (1988) describe a being orientation when they state, "Life is an organic whole, people are people, and it is human to embrace life..." (p. 72). Condon \& Yousef go on to state that this being orientation frequently evokes both envy and pity from the doers - envy for the simplicity and sheer humanity, and pity for the unwillingness of the other to 
alter his condition and improve.

One would expect that in the light of the previous discussion, one's orientation with respect to time would also be a reflection of broader cultural values. As discussed in Chapter III, for Americans time is money, and punctuality a virtue. For many Russians, their agricultural heritage, coupled with the lack of incentives under the communist regime to do things on time, has produced a sense that "time is like the seasons--a time for sowing and a time for reaping and a time for doing little in between" (Richmond, 1992, p. 122).

Two of the questions on the Value Orientation Worksheet related to time. Question III/2 asked; How does time tend to be defined and valued? Three of the students reported that they perceived of their Russian counterparts as defining time like they did (the passage of time is both keenly sensed and highly valued and is something which should be considered a resource to save rather than waste). The other four all reported that while they perceived of time as something which was keenly sensed and highly valued, their perception of Russians was that there was either no consciousness of the passing of time except perhaps in the changing of seasons, or that while time may be sensed to a limited extent, it is thought to occur in big chunks - with no sense that it is highly valuable.

This is an area in which such divergent views can create difficulties in interpersonal as well as international relations. In working on joint projects, 
the activity oriented American with a highly developed sense of time will want to negotiate an agreement quickly, begin work immediately, complete the work as quickly as possible while staying on schedule and under budget. It occurs to me as I write this that perhaps much of the frustration experienced by the Americans involved in both the American students' sojourn in Russia and the Russian athletes' stay in the United States were exacerbated by the perceptual differences and values related to time and activity orientation. As quoted in the review of the literature, "As long as our way of perceiving the world--on which our communication styles and behavior patterns are based--is 'out of awareness,'....It will continue to contribute to misunderstanding and conflict" (Hoopes, 1979, p. 16).

It is the opinion of the researcher that given the long standing "cold war" between the United States and Russia, question II/2 How are personal disagreements and conflicts usually dealt with? also warrants further study. Are the post-sojourn tendencies valid? Do we indeed agree with each other on how to deal with personal disagreements and conflicts, and if so do these same "techniques" apply to group and national issues? In intercultural communication one would be wise to remember Hoopes (1979) warning that no matter what our experience, or how skillful we become in recognizing the cultural dimensions of human relations, we will still find ourselves prisoners of our own limited perceptions. Hastorf (1970) in speaking of social perception further noted that how we categorize and perceive others will influence how 
we behave toward them, and our behavior in turn will influence how they react (p. 13). If we are to move ahead with discussing the thorny global issues which besiege both nations on a daily basis, it behooves us to understand one another's values and perceptions concerning the whole issue of the manner in which disagreements and conflicts are dealt with in our respective nations.

Question 1/1 which asks; To what extent are people generally assumed capable of personal improvement? drew the closest range of response for any of the questions across all of the Value Orientation Worksheets. Post-sojourn responses revealed that all seven students' chose the same response, indicating a perception that their Russian counterparts give equal value to an individuals' learned skills and individual achievement and their background and descent from a particular family.

What is particularly interesting in analyzing this response was that the individual sojourn experience overcame what the orientation did not. There were five category changes after the pre-departure orientation sessions, but the responses indicated that the students' were not in agreement. It appears that something happened in the sojourn experience which influenced the students' reported perceptions concerning what is primarily valued and respected in individuals.

The students' reported perceptions of how their Russian counterparts would answer this question is particularly interesting in light of the strong communal theme found in the literature review. Nowhere in the literature are 
learned skills and individual achievement in life spoken of as important or desired in Russian culture, rather one reads over and over again of the virtues of communal living. Indeed, according to Richmond (1992) the statement "he is not a good collectivist" becomes a stain which is almost impossible to remove. Individuals who push against the flow are considered egotists not achievers. A Russian proverb states: "Together in the mir we will move even mountains" (Richmond, 1992, p.13; Shipler, 1984). Further research is needed to ascertain whether this agreement among the students after the sojourn can be replicated. Is there a major change occurring within Russia concerning the value of learned skills and individual achievement, or were the students prisoners of their own perceptions, observing their Russian hosts from their own unique point of view - comparing them with themselves as "the standard of normal" (Brislin \& Pederson 1976, p.11; Hoopes, 1979).

\section{Limitations and Suggestions for Future Research}

There is a need to expand the databank on the affects of the short-term sojourn. Although much has been written on the impact of long term sojourns, the short-term sojourn has been neglected. I believe that research in this field would be enhanced by taking the following factors into consideration.

1. A larger group of sojourners. Due to the small number of participants in this study one can speak only of tendencies.

2. The study would have been greatly enhanced by the addition of long interviews with each student. The use of the long interview would allow for 
amplification and clarification of aspects of the study which were not possible given the combination of the questionnaire format and the small number of participants. According to McCracken (1988) the long interview gives the interviewer an opportunity to "step into the mind of another person, to see and experience the world as they do themselves" (p.9). The long interview would also have been helpful in situating the responses on the Value Orientation Worksheets into a fuller social and cultural context - were the factors which Hansel (1984) identified as conceivably making a significant difference in the sojourn experience, factors in this study?

2. An equal number of males and females. Although gender was not addressed in this research due to the imbalance of males and females, it might very well be a factor in individual perceptions. Future studies would benefit from an ability to compare and contrast the responses of the participants based on their gender.

3. A fourth set of Value Orientation Worksheets taken within two weeks of the participants' re-entry into the United States. This additional information would provide a baseline for the last worksheet given ten months later. Given the time lag between the sojourn and the post-sojourn worksheet, it is possible that the shifts in the students' responses were not entirely due to the sojourn. Since the students' return to the United States, it has been my observation that some of them are much more attuned to newscasts and articles relating to Russia then before their sojourn. 
4. Add two control groups. One control group would receive no orientation, but would fill out the Value Orientation Worksheets at the same time as the other participants. Using the Value Orientation Worksheet as the basis for discussion in the orientation sessions, I would add a second control group of students who would not go on the sojourn. The first control group provides a baseline for observing the affects of the orientation on the students' perception of Russian and American cultural values, while the second does the same in relation to the sojourn.

\section{EPILOGUE}

It is no longer necessary to travel abroad to experience frequent and prolonged contact with those who are culturally different from ourselves, whether it be a student on a cultural exchange program, the family sent to the United States for a five year business assignment, or the newly arrived immigrant. As the world continues to change, and we become increasingly cognizant of our role in what has been termed the "global village", it will become increasingly important that we are aware of the cultural value differences which motivate and influence individual behavior as well as national policy.

We must recognize that everyone does not think "like me." Even with those who would appear to have been raised in homes with values and lifestyles not unlike our own, there will be differing underlying values, 
perceptions and beliefs which continually influence and direct an individual's behavior and responses. Those values and perceptions which we so often take for granted are not "givens" just because the individual appears to be "like us." Consider my surprise at the responses surrounding time. I anticipated one response, that which concurred with my time values, but found that even with only seven students the responses were quite varied.

With a small number of participants it is impossible to suggest that this research represents the larger world, or even other student athletes traveling abroad. What this study can do, however, is provide insights into the complicated character, organization, and logic of the culture to which these students belong.

Continued research in this field is needed to determine whether or not the tendencies uncovered in this study can be generalized to include a wider population, specifically those American high school students traveling abroad for a short-term sojourn. A deeper understanding of the nature of culture and cultural differences will increase the sojourners ability to recognize and appreciate the alternative solutions and responses adopted by other cultures.

Samovar and Porter (1988) write; "if the human race is to endure in the decades ahead--decades that will, in both time and space, bring all humans closer together in a global community--we must all be able to communicate with people from cultures far removed from our own" (p.viii).

Twenty eight years ago Edward T. Hall wrote; "There is a great need to 
revise and broaden our view of the human situation, a need to be both more comprehensive and more realistic, not only about others, but also about ourselves as well" (1966, p. 6).

If the seven students who participated in this study have come away with a deeper understanding of themselves and their own cultural values coupled with an appreciation of those who are different from themselves, then despite the inability to draw definitive conclusions, thereby adding to the existing body of knowledge concerning short-term sojourns, I will consider this research to have been well worth the considerable time and effort it took to complete. 


\section{REFERENCES}

AFS (1981). AFS Orientation Handbook. 1st ed., AFS International/Intercultural Programs.

AFS (1987). AFS: Intercultural programs. $\underline{6}$, Center for Study of Intercultural Learning.

Albert, E. (1968). Value Systems. The International Encyclopedia of the Social Sciences. 16, 288.

Althen, G. (1988). American Ways. Yarmouth, MA: Intercultural Press.

Bochner, S. (1988). Cultures in conflict: Studies in cross-cultural interaction. New York: Pergamon.

Borden, G. A. (1991). Cultural orientation: An approach to understanding intercultural communication. Englewood Cliffs, NJ: Prentice Hall.

Brislin, R. (1976). Topics in Culture Learning (Vol. IV). Honolulu: East West Center.

Brislin, R. W. \& Pedersen, P. (1976). Cross-cultural orientation programs. New York: Gardner Press.

Brunner, J. S. (1958). Social psychology and perception. In E.E. Macoby, \& E. L. Hartley (eds.) Readings in social psychology (3rd ed.) (p. 86). New York: Holt, Rinehart, and Winston.

Condon, J.C. \& Yousef, F. S. (1975). An introduction to intercultural communication. New York: Macmillan. 
Custine, Marquis de (1989). Empire of the Czar, a journey through eternal Russia. New York: Doubleday, Anchor Books.

Eide, I. (1970). Students as links between cultures, Oslo: Universitesforlaget.

Gorer, G. \& Rickman, J. (1949). The people of great Russia: A psychological study. London: Cresset Press.

Grove, C. E. (1976). Communications Across Cultures: A Report on Cross Cultural Research. Washington, DC: National Education Association of the U.S.

Guizot, F. (1955). Quoted by Hans Kohn in The Mind of Modern Russia. New Brunswick, NJ: Rutgers University Press.

Hall, E. T. (1966). The Hidden Dimension. New York: Doubleday.

Hall, E. T. (1976). Beyond culture. Garden City, NJ: Anchor.

Hansel, B. (1984). Literature Review: Studies of the Impact of a Travel-Abroad Experience. (Research report No. 28). New York: The Research Department. AFS International/Intercultural Programs, Inc.

Harris, P.R., \& Moran, R. T. (1986). Managing cultural differences. Houston: Gulf.

Hastorf, A. H., Schneider, D.J, \& Polefka, J. (1970). Person perception. Reading, MA: Addison-Wesley.

Hingley, R. (1979). The Russian mind. New York: Charles Scribner's Sons. 
Hoffman, J. E. \& Zak, I. (1969). Interpersonal communication and attitude change in a cross-cultural situation. The Journal of Social Psychology, $\underline{78}$, pp. 165-71.

Hofstede, G. (1984). Cultures consequences. Newbury Park, CA: Sage.

Hoopes, D.S. (1979). Intercultural communication concepts and the psychology of intercultural experience. In M. D. Pusch (Ed.), Multicultural education: A cross cultural training approach. (pp. 10-38). Yarmouth, ME: Intercultural Press.

Hoopes, D. S., \& Pusch, M. D. (1979). Definition of terms. In M. D. Pusch (Ed.), Multicultural education: A cross cultural training approach. (pp. 28). Yarmouth, ME: Intercultural Press.

Hoopes, D. S., \& Pusch, M. D. (1979). Teaching Strategies: The methods and techniques of cross-cultural training. In M. D. Pusch (Ed.), Multicultural education: A cross cultural training approach. (pp. 104-255). Yarmouth, ME: Intercultural Press.

Huxley, A. (1989). Along the road: Notes and essays of a tourist. New York: Ecco.

Hyman, H. H. (1953). The value systems of different classes: A social psychological contribution to the analysis of social stratification. In $R$. Bendix, \& S. M. Lipset (Eds.). Class, status and power: A reader in social stratification. (pp. 426-442). Glencoe, IL: The Free Press.

Kagitcibasi, C. (1978). Cross-national encounters: Turkish students in the United States. International Journal of Intercultural Relations, 2, (2), 14059.

Kohls, L. R. (1984). Survival kit for overseas living (2nd ed.). Yarmouth, MA: Intercultural Press. 
Kluckhohn, F. R., \& Strodtbeck F. L., (1961). Variations in value orientations. Evanston, IL: Row, Peterson.

Likhachev, D. S. (1991). Reflections on Russia. (C. Sever, Trans.). Boulder, CO: Westview.

Lee, J.A. (1966, March-April). A cultural analysis in overseas operations. Harvard Business Review.

Leonard, E. W. (1964). Attitude change in a college program of foreign study and travel. Educational Record, 45, pp. 173-81.

Littlejohn, S. W. (1989). Theories of human communication (3rd ed.). Belmont, CA: Wadsworth.

McCracken, G. (1988). The long interview. Newbury Park, CA: Sage.

Mead, M. (1951). Soviet attitude toward authority: An interdisciplinary approach to problems of soviet character. New York: William Morrow.

Nash, D. (1976). The personal consequences of a year of study abroad. Lournal of Higher Education, 느, (2), 191-203.

Parsons, T. (1951). The social system. New York: The Free Press.

Peabody, D. (1985). National Characteristics. London: Cambridge Unniversity Press.

Pearce, P. L. (1982). Tourists and their hosts: Some sociological and psychological effects of intercultural contact. In Stephen Bochner (Ed.), Cultures in Contact (pp. 199-221). Oxford: Pergamon Press. 
Porter, R. \& Samovar, L. (1988). Approaching intercultural communication. In L. Samovar \& R. Porter (Eds). Intercultural communication: A reader (5th ed.) (pp. 15-44). Belmont, CA: Wadsworth.

Pusch, M. D. (1979). Teaching strategies: The methods and techniques of cross-cultural training. In M. D. Pusch (Ed.), Multicultural education: A cross training approach (p.106-204). Yarmouth, ME: Intercultural Press.

Richmond, Y. (1992). From nyet to da. Yarmouth, MA: Intercultural Press.

Rubin, R. B., Rubin, A. M., \& Piele, L. J. (1986). Communication research: Strategies and sources. Belmont, CA: Wadsworth.

Rokeach, M. (1969). Beliefs, attitudes and values: A Theory of organization and change. San Francisco: Jossey-Bass.

Rokeach, M. (1973). The nature of human values. New York: Free Press.

Senge, P. M. (1990). The fifth discipline. New York: Doubleday.

Schutz, A. (1967). The phenomenology of the social world. (G. Walsh \& F. Lehnert, Trans.) Northwestern University Press.

Shlapentokh, V. (1989). Public and private life of the Soviet people. New York: Oxford University Press.

Singer, M. R. (1982). Culture: A perceptual approach. In L. Samovar \& R. Porter (Eds.). Intercultural communication: A reader. (pp. 54-62). Belmont, CA: Wadsworth.

Sitaram, K. S. \& Haapanen, L. W. (1979). The role of values in intercultural communication. In M. K. Asante \& C. A. Blake (Eds.) Handbook of intercultural communication (pp. 147-160). Beverly Hills, CA: Sage Publications. 
Smith, H. P. (1955). Do intercultural experiences affect attitudes? Journal of Abnormal and Social Psychology, 51, pp. 469-77.

Steward, E. C. (1971). American cultural patterns: A cross cultural perspective. Washington, D.C.: Society for Intercultural Education, Training and Research.

Tocqueville, A. de. (1969). Democracy in America. P. J. Mayer \& G. Lawrence (Ed., Trans.) (Vol. 1). Garden City, New York: Doubleday.

Ting-Toomey, S. (1984). Qualitative research: An overview. In W. B. Gudykunst and Y. Y. Kim (Eds.), Methods for intercultural communication research (pp.169-184). Beverly Hills, CA: Sage.

Tucker, R., Weaver, L., II, Berryman-Fink, C. (1981). Research in speech communication. Englewood Cliffs, NJ: Prentice-Hall.

Vornberg, J. A. \& Grant, R. T. (1976). Adolescent cultural acquaintance experiences and ethnic group attitudes. Adolescence, 11, pp. 601-08.

Willis, D. K. (1985). KLASS: How Russians really live. New York: St. Martin's Press. 
APPENDIX A

VALUE ORIENTATION WORKSHEET

Cornelius Grove American Field Service 


\section{Value Orientation Worksheet Instructions}

For each concern, mark the point on the continuum that seems to come closest to describing the value orientation that is characteristic, on the whole, of the people who are in the mainstream of life in your home community.

You will also be given instructions to mark the point on the continuum that you feel best describes the value orientation that is characteristic of your Russian host community.

You will use the worksheet marked American for your own perceptions, and that marked Russian for your perception of Russian values.

\section{EXAMPLE:}

To whom does an individual have primary responsibility?

\begin{tabular}{lllll}
\multicolumn{1}{c}{1.0} & 1.5 & \multicolumn{1}{c}{2.0} & 2.5 & \multicolumn{1}{c}{3.0} \\
$\begin{array}{l}\text { To himself or } \\
\text { herself } \\
\text { personally }\end{array}$ & $\begin{array}{l}\text { To other people } \\
\text { such as family } \\
\text { members or } \\
\text { close friends. }\end{array}$ & $\begin{array}{l}\text { To a supreme } \\
\text { being or } \\
\text { philosophic } \\
\text { ideal. }\end{array}$
\end{tabular}

If you think that on the whole, people in your home community act as though their primary responsibility is to family members and/or close friends, you would check the continuum at 2.0. If you think that they act as though their primary responsibility is somewhat to themselves personally and somewhat to other people, you would check the continuum somewhere in the vicinity of 1.5 . You may check the continuum at any point whatsoever.

Keep in mind that purpose of this exercise is to identify fifteen central tendencies in the value orientations of your home community and your Russian host community, and to locate them on a continuum that represents the range of possibilities to people at all times and places. You are, therefore, likely to have to stretch your imagination to consider values that are different from your own, but equally meaningful to people who hold them. Remember that we are not looking for absolutes, only tendencies. 


\section{VALUE ORIENTATION WORKSHEET}

\section{THE INDIVIDUAL}

II To what extent are people generally assumed capable of personal improvement?

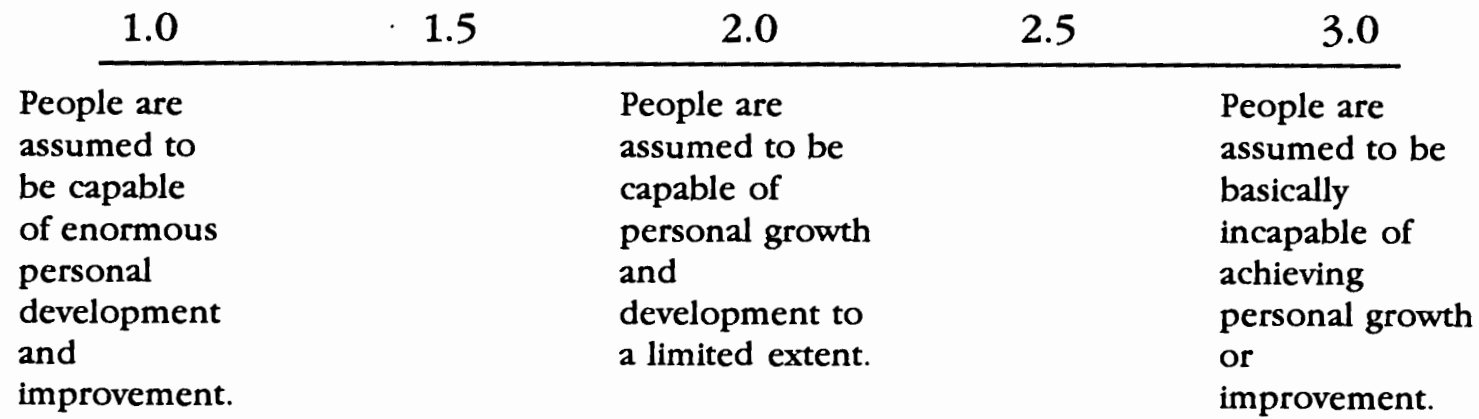

1/2 What do individuals tend to assume about the role of fate (chance) in their lives?

$\begin{array}{lllll}1.0 & 1.5 & 2.0 & 2.5 & 3.0\end{array}$

Fate is assumed

to have little or

no importance;

individuals

assume that

they are very

largely masters

of their own

destinies and

can influence

future events.
Fate is assumed

to play a

moderate role

in an

individual's life,

but the

individual is

assumed to

exercise some

control over his

or her own

destiny.
Fate is assumed to play a major role in an individual's life; individuals assume they have little or no control over their own destinies. 
I. The Individual, cont.

I/3 What effect does one's sex tend to have on one's responsibilities and roles in the family, among friends and co-workers, and in society?

\begin{tabular}{|c|c|c|c|}
\hline 1.0 & 1.5 & 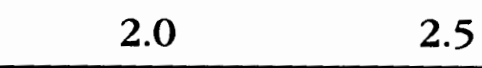 & 3.0 \\
\hline $\begin{array}{l}\text { Distinct and } \\
\text { rigidly defined } \\
\text { roles and } \\
\text { responsibilities } \\
\text { are assumed } \\
\text { because one is } \\
\text { male or female; } \\
\text { rarely is there } \\
\text { any overlap in } \\
\text { expectations of } \\
\text { the two sexes. }\end{array}$ & - & $\begin{array}{l}\text { Being male or } \\
\text { female has } \\
\text { moderate power } \\
\text { to determine } \\
\text { one's roles and } \\
\text { responsibilities, } \\
\text { but one's } \\
\text { interests and } \\
\text { abilities are also } \\
\text { taken into } \\
\text { account. }\end{array}$ & $\begin{array}{l}\text { Being male or } \\
\text { female has little } \\
\text { or nothing to } \\
\text { do with the } \\
\text { roles and } \\
\text { responsibilities } \\
\text { that one } \\
\text { assumes in the } \\
\text { family, among } \\
\text { co-workers and } \\
\text { friends, and in } \\
\text { society. }\end{array}$ \\
\hline
\end{tabular}

I/4 What is the most generally approved procedure by which people arrive at conclusions and make decisions?

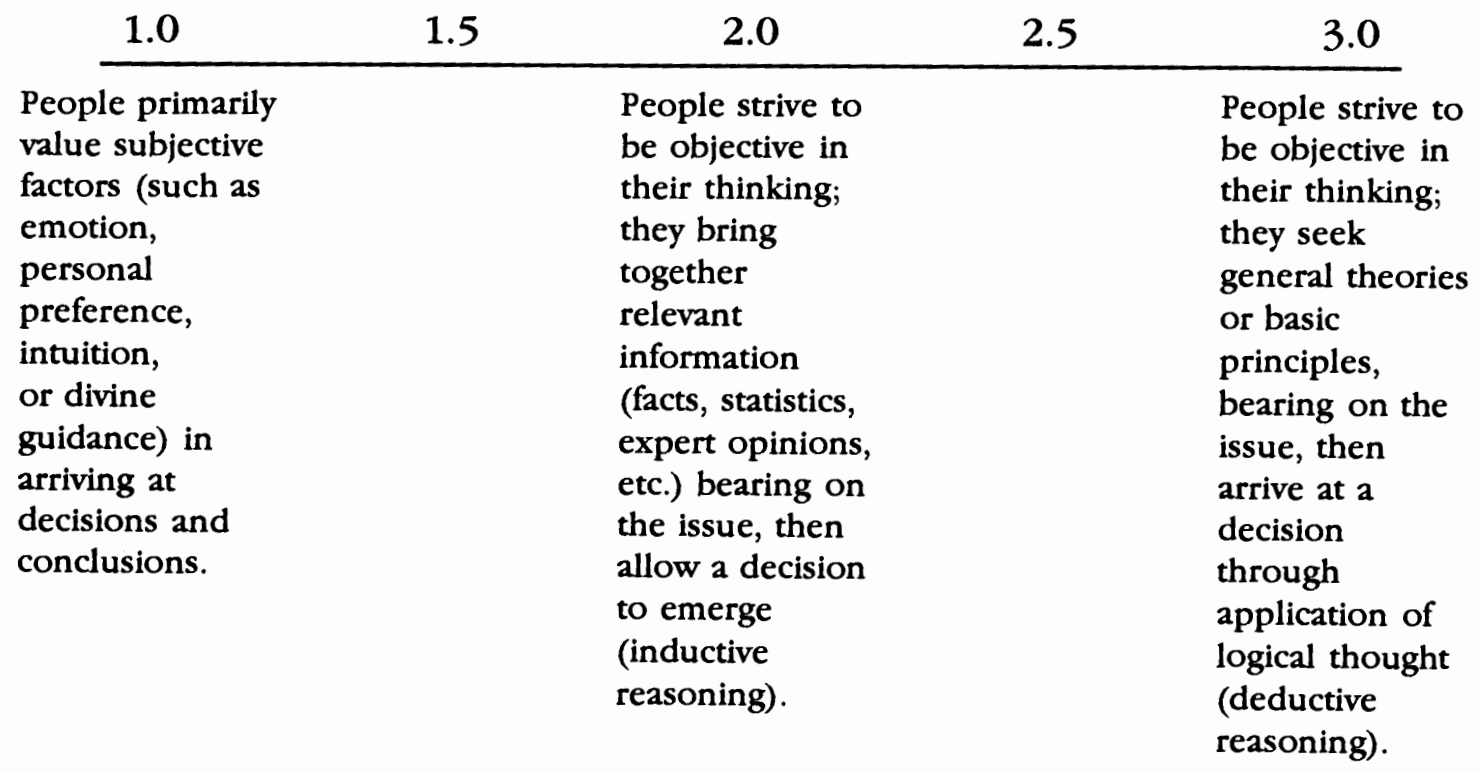


I. The Individual, cont.

1/5 What is primarily valued and respected in individuals?

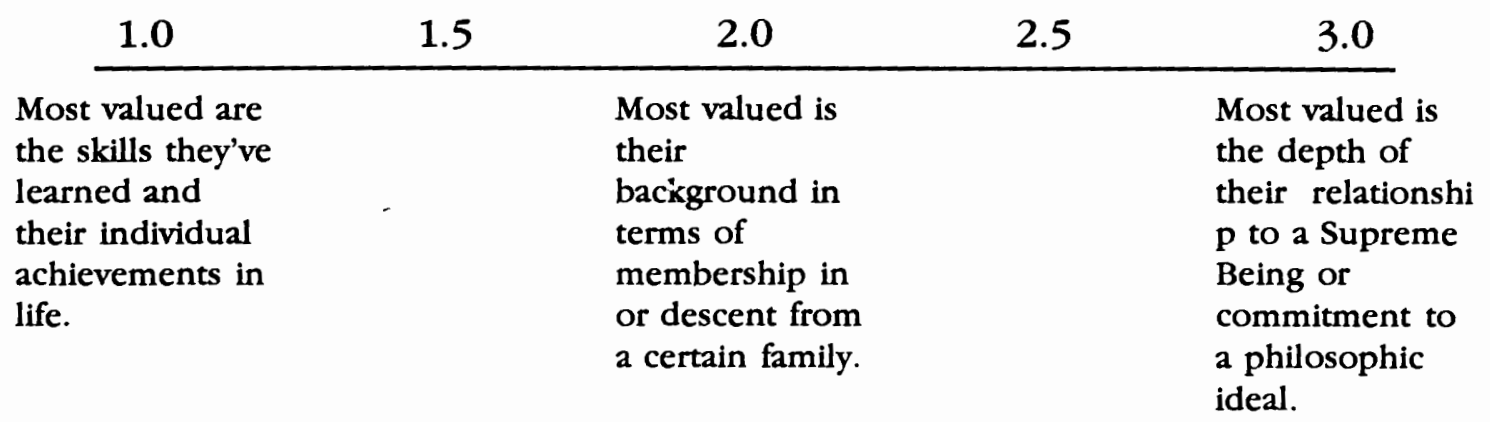

I/6 On what basis do most people often judge procedures, events, and ideas?

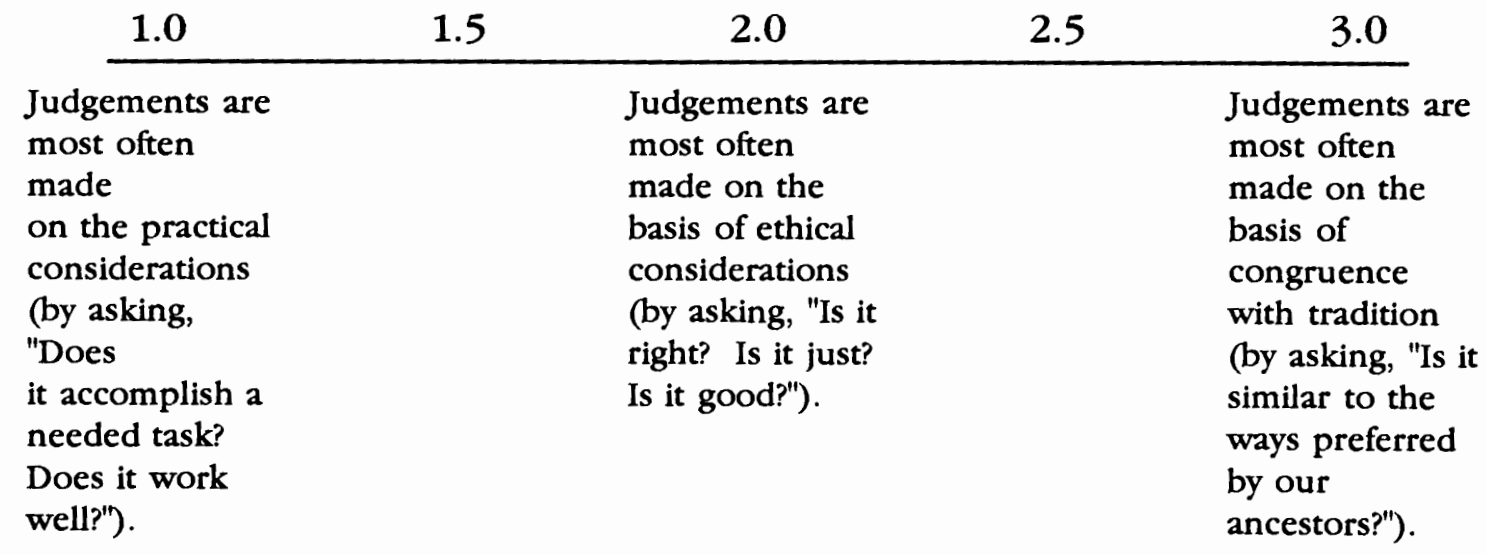




\section{SOCIAL RELATIONSHIPS}

II/1 What type of relationship with others tends to be suggested by the terms "friend" and "friendship"?

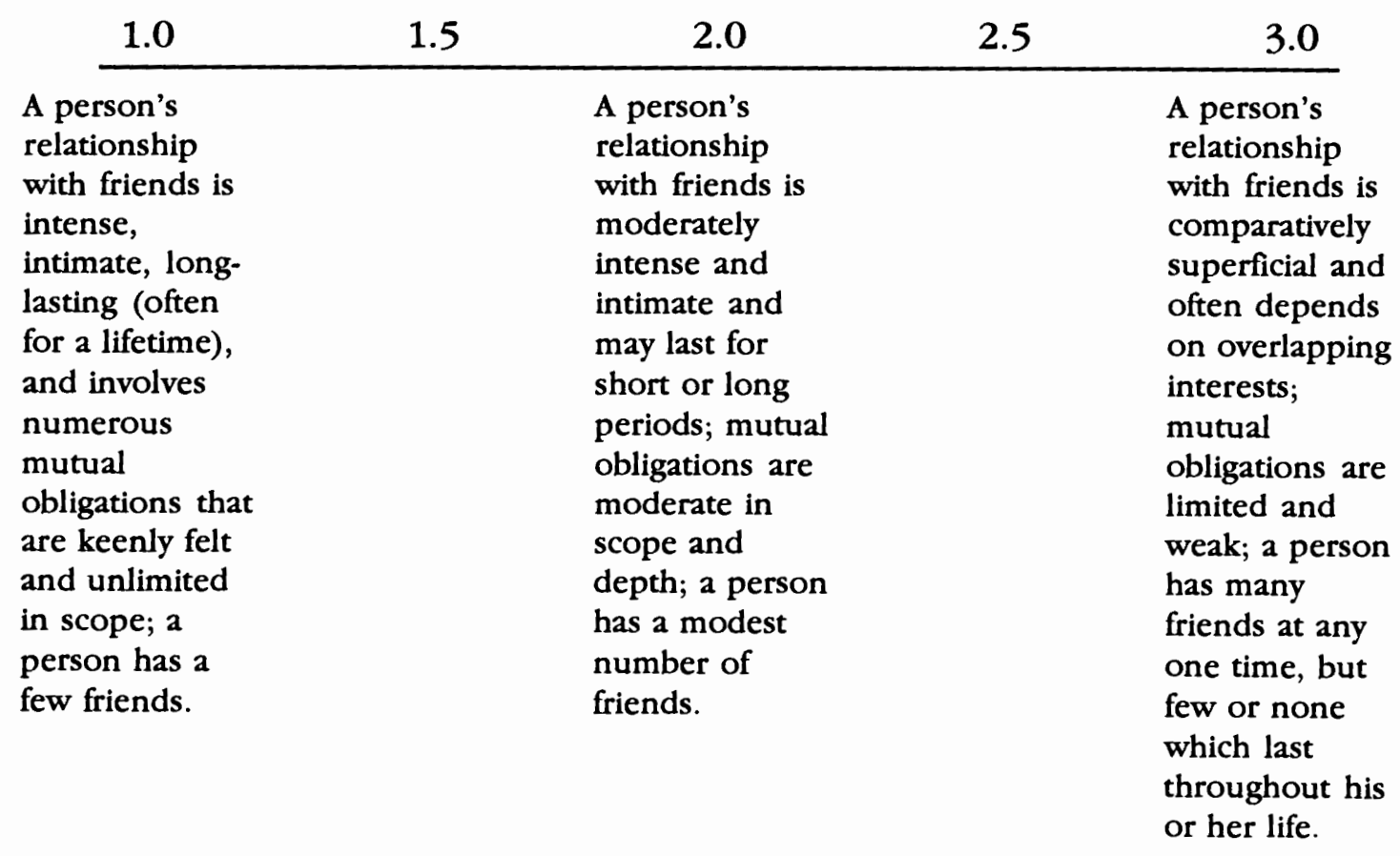

II/2 How are personal disagreements and conflicts usually dealt with?

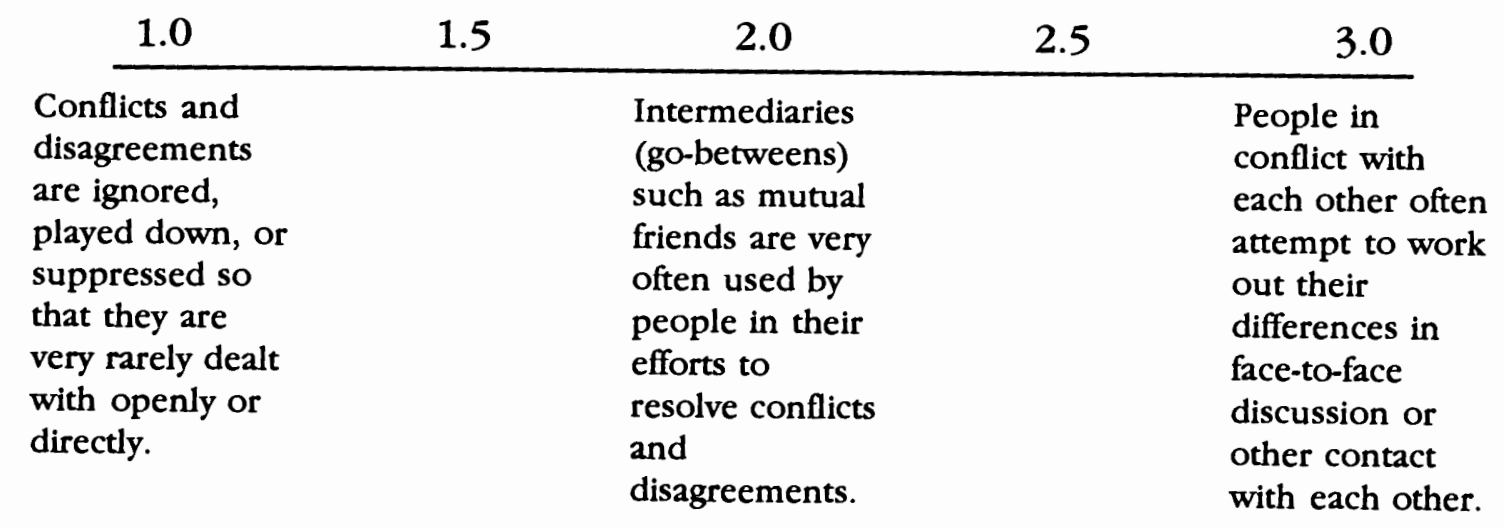


II. Social Relationships, cont.

II/3 What is the primary orientation of people with respect to time?

$\begin{array}{lllll}1.0 & 1.5 & 2.0 & 2.5 & 3.0 \\ \begin{array}{l}\text { The past is of } \\ \text { primary interest } \\ \text { and importance. }\end{array} & \begin{array}{l}\text { The present is } \\ \text { of primary } \\ \text { interest and } \\ \text { importance. }\end{array} & \begin{array}{l}\text { The future is of } \\ \text { primary interest } \\ \text { and importance. }\end{array}\end{array}$

II/4 To what degree do people tend to remain loyal to groups and organizations?

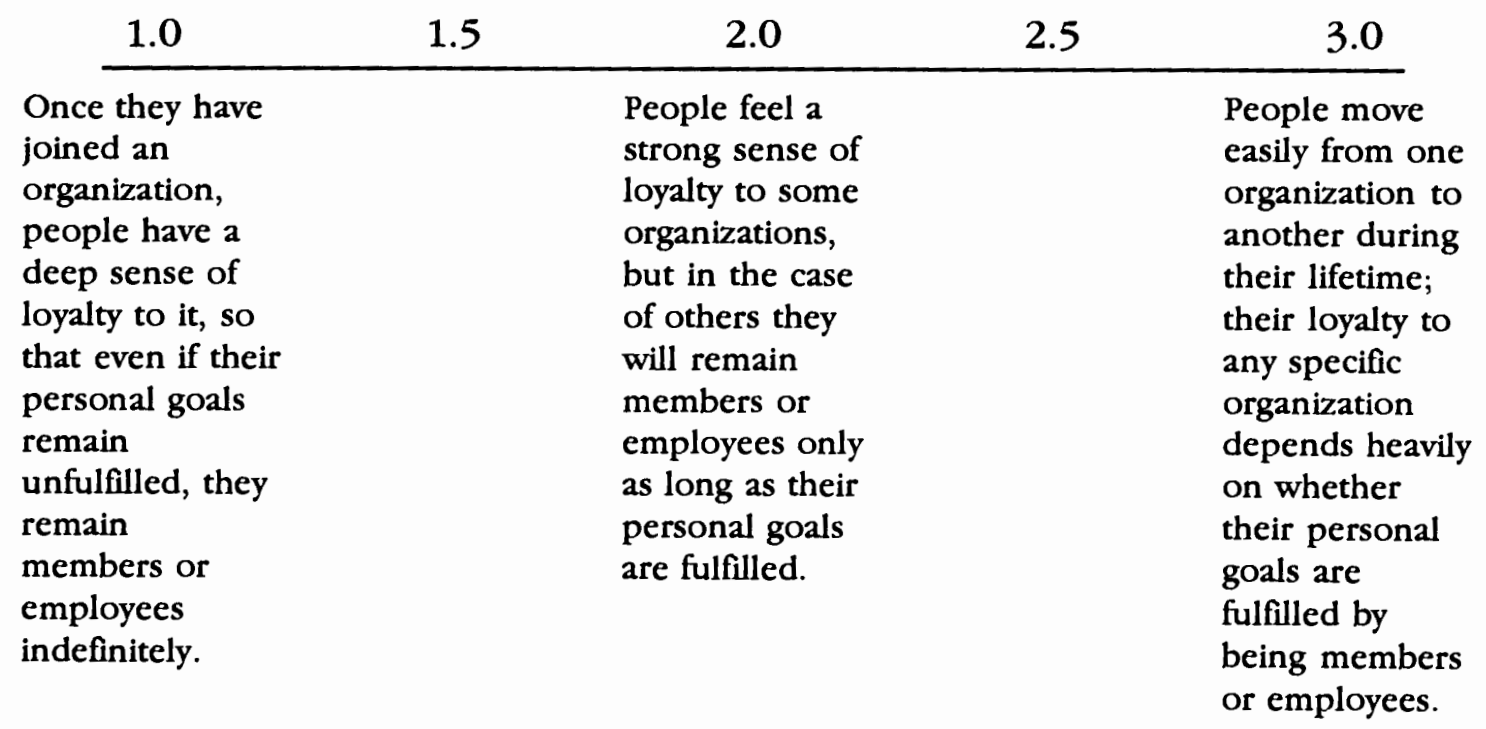


II. Social Relationships, cont.

II/5 How do people usually relate to others of higher or lower social status?

\begin{tabular}{ll}
1.0 & 1.5 \\
\hline
\end{tabular}

Although people

are aware of

differences in

social status,

they ignore or

play down such

differences in

almost all their

relationships

with others;

informality

prevails almost

all the time.
2.0

Social status

differences are

moderately

important in

social

relationships; in

a few situations,

very formal or

ritualized

behavior is

observed when

higher or lower

status people

meet.

2.5

3.0

Social status
differences carry
great weight in
almost all social
relationships; in
most situations,
formality or
ritual governs
behavior when
higher and
lower status
people are
together.

Social status

differences carry

great weight in

almost all social
relationships; in

most situations,

formality or

ritual governs

behavior when

higher and

people are

together.

II/6 To what extent do people tend to feel bound or obligated by their membership in a particular family or clan?

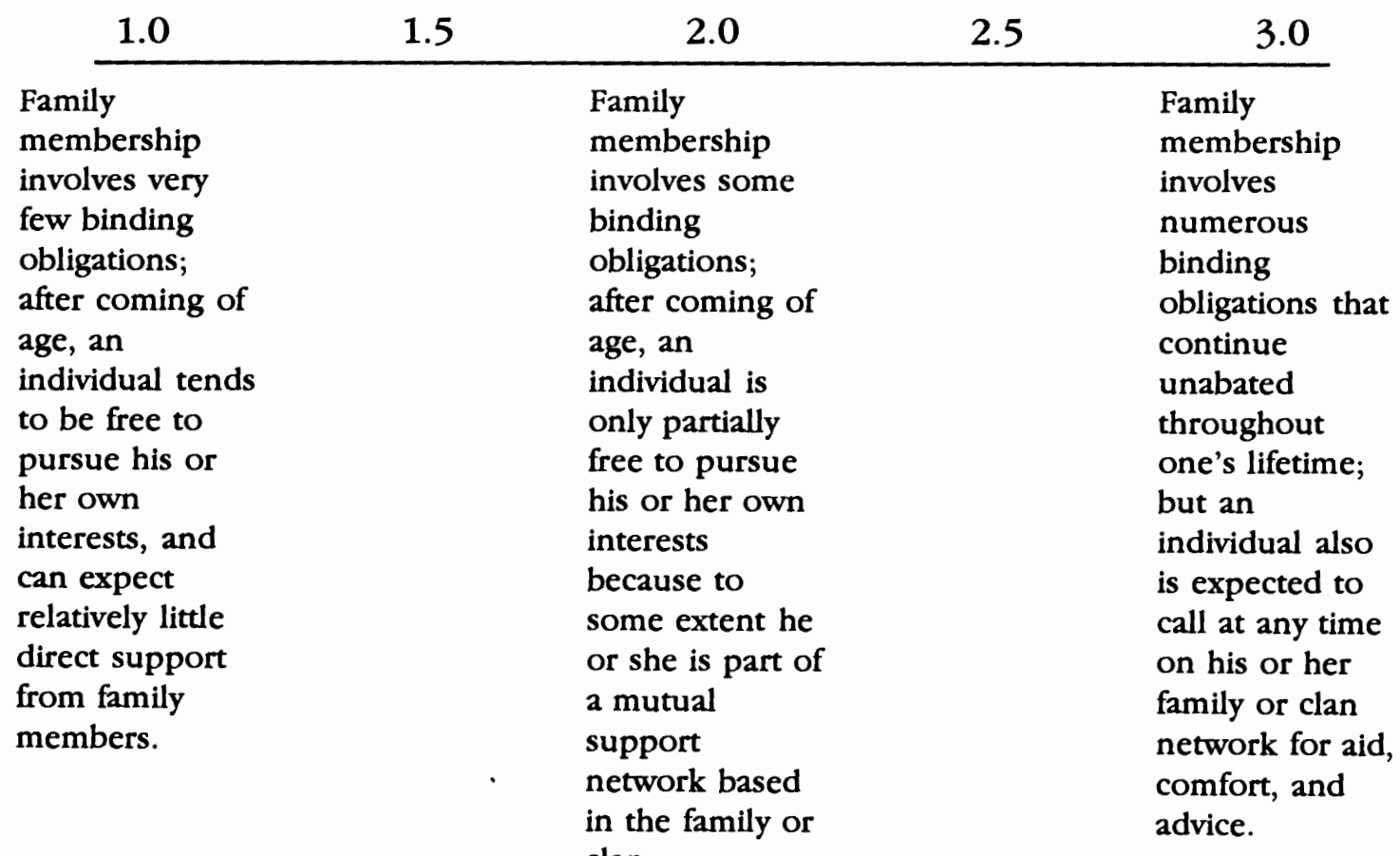




\section{NATURE AND THE SUPERNATURAL}

III/1 How does the interaction between humans and nature tend to be conceived?

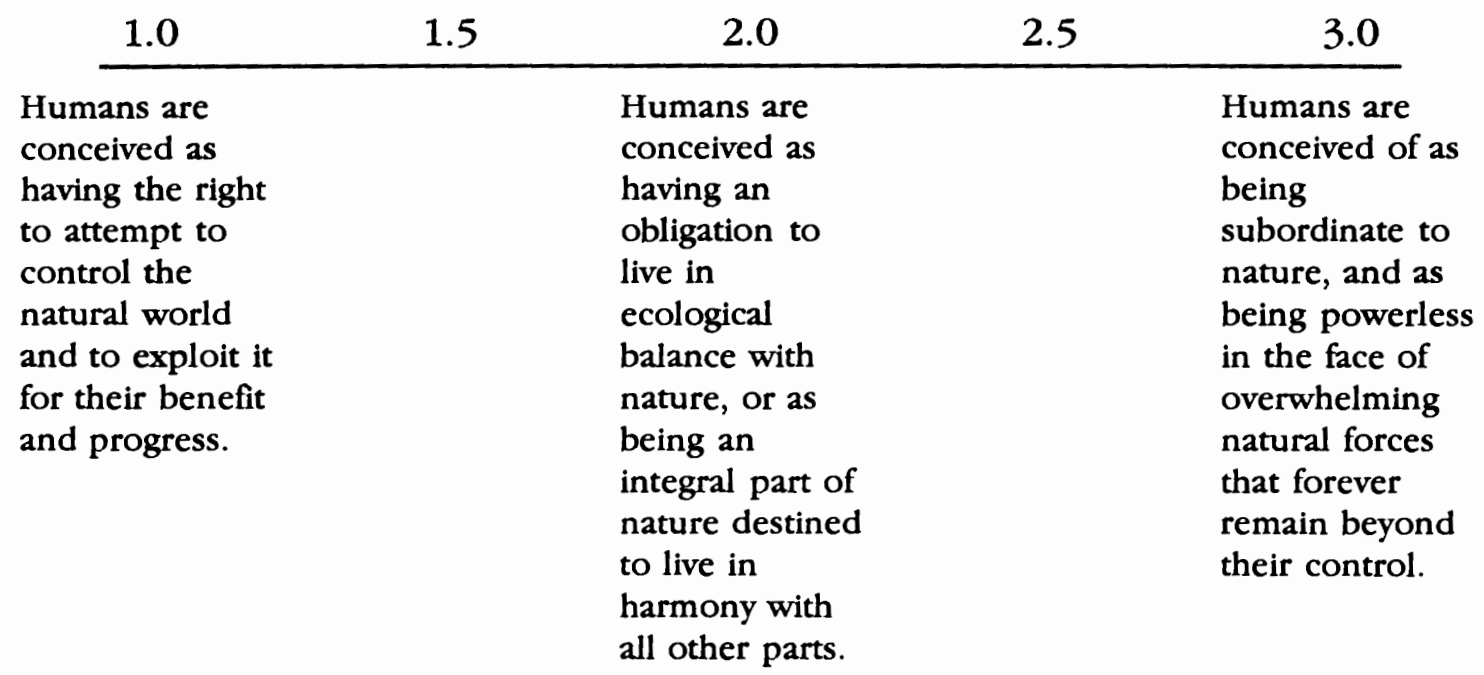

III/2 How does time tend to be defined and valued?

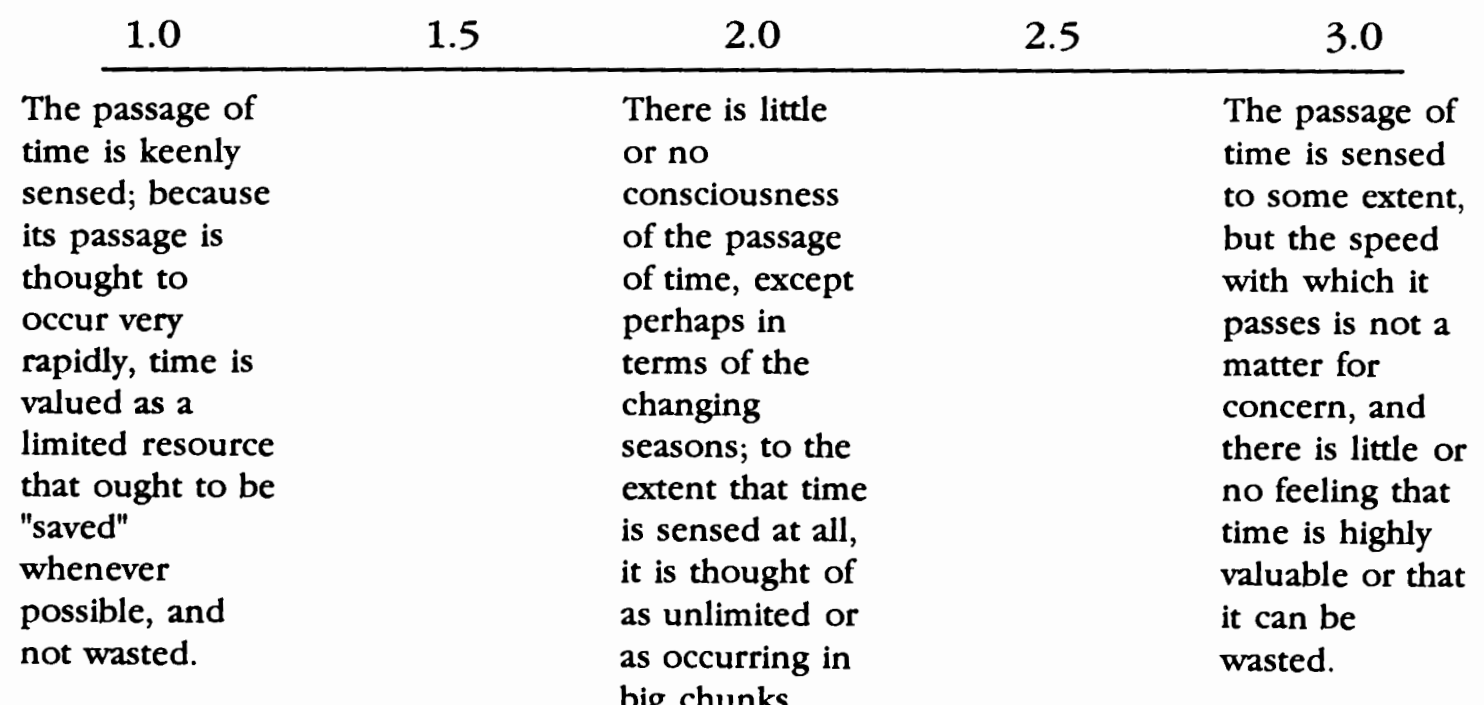


III. Nature and the Supernatural, cont.

III/3 To what extent are material things and the fruits of human progress assumed to be available to human beings?

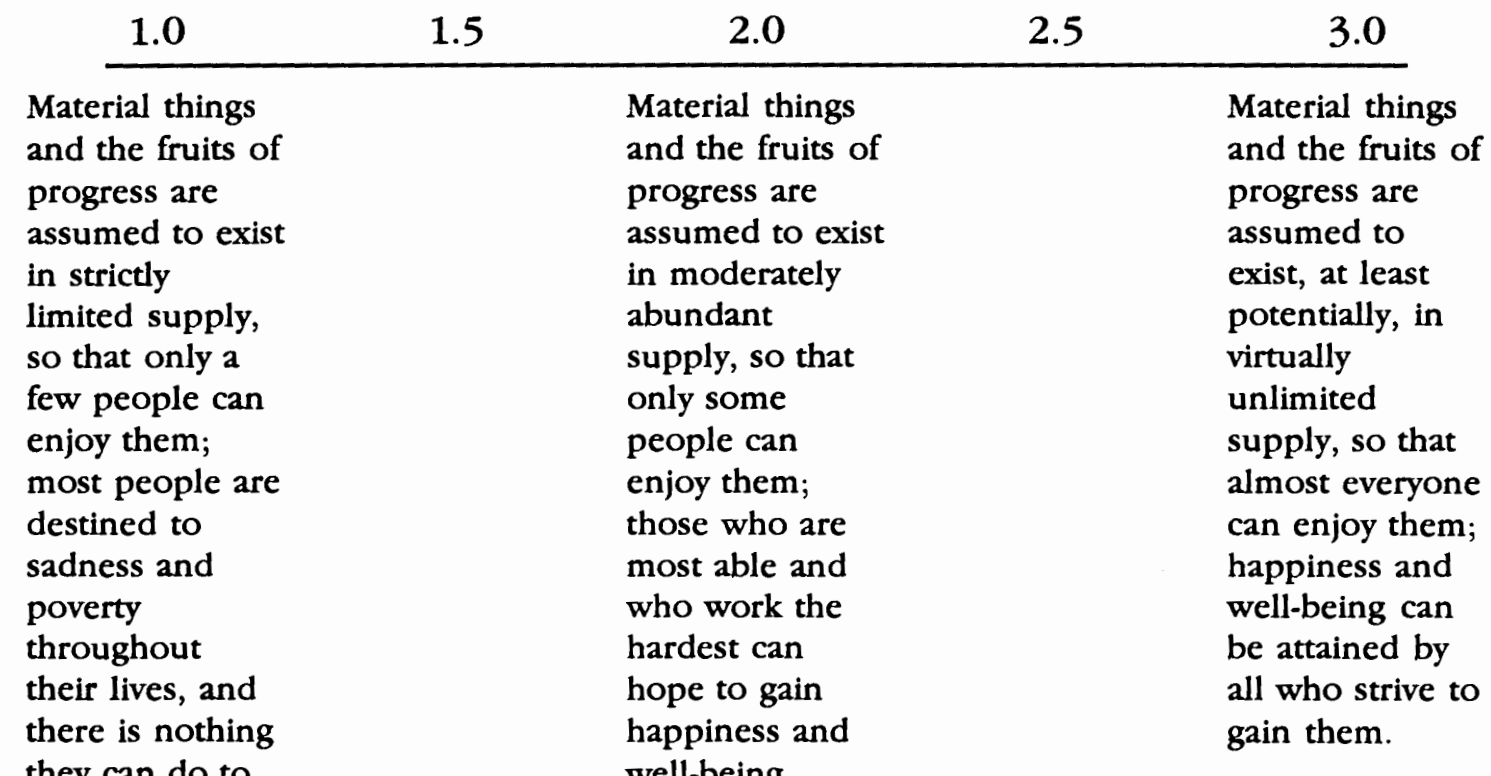

they can do to

well-being.

change their

condition. 